Ahmed S. Shehata, Qing Xiao, Mohamed ElShaib, Ashraf Sharara, Day Alexander

NOTICE: this is the author's version of a work that was accepted for publication in the Energy. Changes resulting from the publishing process, such as final peer review, editing, corrections, structural formatting, and other quality control mechanisms may not be reflected in this document. Changes may have been made to this work since it was submitted for publication. This manuscript was accepted for publishing on 15 November 2016. A definitive version will subsequently published in the Journal of Energy. 


\section{Comparative Analysis of Different Wave Turbine Designs \\ 2 Based on Conditions Relevant to Northern Coast of Egypt}

3 Ahmed S. Shehata ${ }^{1,2 *}$, Qing Xiao ${ }^{1}$, Mohamed El-Shaib ${ }^{2}$, Ashraf Sharara ${ }^{2}$, Day

\section{Alexander ${ }^{1}$}

1) Department of Naval Architecture, Ocean and Marine Engineering, University of Strathclyde, Glasgow G4 0LZ, UK.

2) Marine Engineering Department, College of Engineering and Technology, Arab Academy for Science Technology and Maritime Transport, P.O. 1029, AbuQir, Alexandria, Egypt.

* Corresponding Author: Ahmed S. Shehata, E-mail address: ahmed.mohamed-ahmedshehata@strath.ac.uk

\section{Abstract}

Wave energy has a great potential to solve the unrelenting energy deficiency in Egypt. The present work recommends Wells turbine as a suitable choice for the Egyptian coasts due to its simple and efficient operation under low input air flow. In addition, the possibility of extracting the wave energy from the Egyptian coasts was investigated using the oscillating water system based on real data from the site. To achieve this purpose, two-dimensional numerical models for Wells turbine airfoils, functioning under sinusoidal wave flow conditions, were built. Moreover, the running and starting characteristics under sinusoidal-flow conditions were investigated using a mathematical code. The results were discussed using the first law analysis, in addition to the second law analysis by using the entropy generation minimization method. It was found that the NACA0015 airfoil always gives a global entropy generation rate that is less than other airfoils by approximately $-14 \%,-10.3 \%$ and $-14.7 \%$ for the sinusoidal wave with time periods equal to 4, 6 and 8 seconds respectively. Moreover, the effects 
1 of blade profile, time period and solidity on the output power $(\mathrm{kW})$ value were

2 discussed.

3 Keywords: Wells turbine; Entropy generation; CFD; Analytical model; Sinusoidal 4 wave; Egyptian Coasts.

\begin{tabular}{|c|c|c|}
\hline \multicolumn{3}{|c|}{ Nomenclature } \\
\hline A & The total blade area. $A=(\mathrm{z} \mathrm{c} \mathrm{b}), \mathrm{m}^{2}$ & $S_{g e n}$ Local entropy generation rate $\left(\mathrm{W} / \mathrm{m}^{2} \mathrm{~K}\right)$ \\
\hline$A_{r}$ & Rotor area $=\pi R_{m}^{2}, \mathrm{~m}^{2}$ & $S_{G} \quad$ Global entropy generation rate $(\mathrm{W} / \mathrm{K})$ \\
\hline $\mathrm{a}$ & Margin distance for the end plate, $\mathrm{m}$ & $S_{i j} \quad$ Mean strain rate \\
\hline $\mathrm{b}$ & Blade Span , m & $S_{t} \quad$ Thermal entropy generation rate $\left(\mathrm{W} / \mathrm{m}^{2} \mathrm{~K}\right)$ \\
\hline c & Blade chord , m & $S_{V}$ Viscous entropy generation rate $\left(\mathrm{W} / \mathrm{m}^{2} \mathrm{~K}\right)$ \\
\hline$C_{D}$ & Drag force coefficient & $T_{o} \quad$ Reservoir temperature $(\mathrm{K})$ \\
\hline$C_{L}$ & Lift force coefficient & $\begin{aligned} t_{\sin } & \text { The time period for sinusoidal wave } \\
& =1 / f, \mathrm{sec}\end{aligned}$ \\
\hline $\mathrm{C}_{\mathrm{P}}$ & Power coefficient & $T_{L} \quad$ Loading torque $\mathrm{N} \mathrm{m}$ \\
\hline$C_{T}$ & Torque coefficient & TSR Tip speed ratio $=\frac{\omega R m}{V_{A m}}$ \\
\hline $\mathrm{D}$ & Drag Force , $\mathrm{N}$ & $\begin{array}{l}\bar{u}_{i} \text { Reynolds Averaged velocity component in } \\
\text { i direction }(\mathrm{m} / \mathrm{s})\end{array}$ \\
\hline$D_{r}$ & Rotor diameter , m & Axial velocity $=V_{A} \sin \left(\frac{2 \pi t}{T}\right), \mathrm{m} / \mathrm{s}$ \\
\hline$f$ & Wave frequency, $\mathrm{Hz}$ & Maximum value of axial velocity, m/s \\
\hline $\mathrm{F}_{\mathrm{A}}$ & Axial Force , N & Resultant air velocity , $\mathrm{m} / \mathrm{s}$ \\
\hline $\mathrm{F}_{\mathrm{t}}$ & Tangential Force, $\mathrm{N}$ & Initial velocity for computation $(\mathrm{m} / \mathrm{s})$ \\
\hline g & $\begin{array}{l}\text { Leading edge offsetting of a blade } \\
\text { from an axis , m }\end{array}$ & Output power coefficient \\
\hline I & Moment of inertia , $\mathrm{kg} \mathrm{m}^{2}$ & $W_{r e v} \quad$ Reversible work \\
\hline $\mathrm{L}$ & lift Force , N & Inertia coefficient \\
\hline$\Delta \mathrm{p}$ & $\begin{array}{l}\text { Pressure difference across } \\
\text { the turbine }, N / \mathrm{m}^{2}\end{array}$ & Loading torque coefficient \\
\hline
\end{tabular}




\begin{tabular}{|llll|}
\hline $\mathrm{Q}$ & $\begin{array}{l}\text { Flow rate through the rotor area } \\
, \mathrm{m}^{3} / \mathrm{sec}\end{array}$ & $\mathrm{Z}$ & Number of blades \\
$R_{h}$ & Rotor radius at hub, $\mathrm{m}$ & $\alpha$ & $\begin{array}{l}\text { Angle of attack- the angle between the } \\
\text { chord line and the direction of the fluid } \\
\text { velocity }, \text { degree }\end{array}$ \\
$R_{m}$ & Mean rotor radius $=\frac{R_{t}+R_{h}}{2}, \mathrm{~m}$ & $\eta$ & Mean turbine efficiency \\
$R_{r}$ & Rotor radius, $\mathrm{m}$ & $\boldsymbol{\rho}$ & Air specific density, $\mathrm{kg} / \mathrm{m}^{3}$ \\
$R_{t}$ & Rotor radius at tip, $\mathrm{m}$ & $\sigma$ & Turbine solidity $=\frac{\mathrm{z} \mathrm{C}}{2 \pi \mathrm{R}}$ \\
$\mathrm{Q}$ & Flow rate through the rotor area & $\boldsymbol{\phi}$ & Flow coefficient \\
$\mathrm{m}^{3} / \mathrm{sec}$ & &
\end{tabular}

\section{Introduction}

3 Egypt is now struggling to meet its own energy needs, experiencing one of its most

4 serious energy crises for decades. The number of residents has increased by a million

5 people over the past six months only, and global warming has caused an increase in the

6 use of air conditioning in summer. Egypt's demand for electricity is growing rapidly

7 and the need to develop alternative power resources is becoming ever more urgent,

8 which necessitates looking for renewable energy options to help meet the increasing

9 demand. For this end, the development of the renewable energy industry has become a

10 priority over the recent years for the Egyptian government. The utilization of wave

11 energy systems has escalated significantly over the past two decades, generally

12 depending on oscillating water column (OWC) concept [1-3]. Wells turbine is one of

13 the most efficient OWC technologies [4]. The characteristic feature of Wells turbine is

14 that oscillating air flow produces a single direction rotation of the rotor without the use

15 of a rectifying valve [5-9]. Wells turbine is usually characterized by four digit double 
1 zero NACA profile [10-13], where the shape of the NACA four digit profiles is

2 determined by three parameters: the camber (first digit), the position of the camber

3 (second digit), and the percentage of thickness to chord (third and fourth digits). Hence,

4 profiles without a camber are symmetrical (NACA 00XX).

5 The overall performance of several design types of Wells turbine were investigated in

6 [14] by using a semi-empirical method for predicting the turbine's performance in [15].

7 Similar comparisons were undertaken using an experimental measurement in [16]. It

8 was observed that the contra-rotating turbine had an operational range which was

9 similar to that of the monoplane turbine with guide vanes, and achieved similar peak

10 efficiency. However, the resulting flow from the contra-rotating turbine was better than

11 the monoplane turbine with guide vanes in the post-stall regime.

12 In order to improve the performance of the Wells turbine, the effect of end plate on the 13 turbine characteristics was investigated in $[17,18]$. Using an experimental model and 14 CFD method, it was shown that the peak efficiency increased by $4 \%$ approximately, 15 compared to the Wells turbine without an end plate. The calculations of the blade 16 sweeps for the Wells turbine were investigated using a numerical code by [19] and 17 experimentally with quasi-steady analysis in [20]. As a result, it was found that the 18 performance of the Wells turbines was influenced by the blade sweep area. To achieve 19 a high performance for the turbine, the appropriate sweep ratio selected was found to 20 be $35 \%$. In addition, setting the blades at their optimum pitch angle during compression 21 and suction was expected to substantially improve turbine efficiency [8, 21-28]. This 22 setting for the blades is achieved by the turbine manufacturer in such a way that allows 23 the turbine blades to rotate around their axis with an angle equals to \pm optimum blade 24 setting pitch angle. Furthermore, two-stage Wells turbines with symmetric and non- 
1 symmetric airfoils were investigated in [29]; the numerical algorithms were used to

2 estimate the optimum shape of the airfoil with an increase of efficiency (by $2.1 \%$ ) and

3 of tangential force coefficient (by 6\%), compared to the standard NACA 2421.

4 Exergy analysis was performed using the numerical simulation for steady state biplane

5 Wells turbines in [30], where the upstream rotor had a design point second law

6 efficiency of $82.3 \%$, although the downstream rotor second law efficiency was equal to

$7 \quad 60.7 \%$. The entropy generation, due to viscous dissipation, around different $2 \mathrm{D}$ airfoil

8 sections for Wells turbine was recently investigated by the authors in $[31,32]$. When

9 Reynolds number increased from $6 \times 104$ to $1 \times 105$, the total entropy generation

10 increased correspondingly by more than two folds for both airfoils. However, when

11 Reynolds number further increased further to $2 \times 105$, the total entropy generation

12 exhibited unintuitive values ranging from $25 \%$ less to $20 \%$ higher than the

13 corresponding value at Reynolds number $=1 \times 105$. The efficiency of four different

14 airfoils in compression cycle was found to be higher than suction cycle at a two-degree

15 angle of attack. But when the angle of attack increased, the efficiency of suction cycle

16 increased more than the compression one. This study suggested that there is a possible

17 existence of a critical Reynolds number at which viscous irreversibilities take minimum

18 values. Moreover, a comparison of total entropy generation, due to viscous dissipation,

19 between a suggested design (variable chord) and a constant chord Wells turbine was

20 presented in [33]. The detailed results demonstrated an increase in static pressure

21 difference around new blade and a $26.02 \%$ average decrease in total entropy generation

22 throughout the full operating range.

23 Most of the researchers investigated the performance of different airfoils designs and

24 different operational conditions where analyzing the problem was based only on the 
1 parameter of first law of thermodynamics. It is essential to look at the second law of

2 thermodynamics to form a deeper understanding of the problem, since it has shown

3 very promising results in many applications, such as wind turbine in [34-39] and gas

4 turbine in [40-44]. A numerical optimization algorithm based on CFD simulation was

5 implemented in order to optimize the blade pitch angle in $[45,46]$. The standard

6 NACA0021 and an optimized profile (AOP) were numerically investigated. The 7 present CFD optimization results showed that the optimum blade pitch angle for 8 NACA0021 was +0.3 degree while that of the AOP was equal to +0.6 degree. The 9 present airfoils with the optimized pitch angle showed an average efficiency with an 10 improvement of $3.4 \%$ for standard NACA0021 and $4.3 \%$ for the AOP.

11 The most bustling with life coast of the Southern Mediterranean Basin is the Egyptian 12 coast, lying between the Nile Delta and the Libyan borders, with a potential of above $133.35 \mathrm{~kW} / \mathrm{m}$ wave power in summer and $6.8 \mathrm{~kW} / \mathrm{m}$ in winter $[47,48]$, and wave energy 14 of about $36003 \mathrm{kWh} / \mathrm{m}$. The most active sea states have significant wave heights 15 ranging between 1 and $4 \mathrm{~m}$, and wave energy periods between 4 and 8 second. The 16 regions with increased wave energy potential are mainly the western and southern 17 coastlines of Cyprus Island, the sea area of Lebanon and Israel, as well as the coastline 18 of Egypt, especially around Alexandria. The significant differences between the sea in 19 Egypt and other seas are that the sea wave in Egypt is relatively low but also stable. 20 Hence, the potential wave energy can be revealed and exploited [49]. Otherwise, sea 21 states with wave heights greater than $5 \mathrm{~m}$ are not very important for the annual energy $22[50]$.

23 The objective of this work is to carry out a study to prove that the Wells turbine could 24 be a suitable wave energy extractor for the Egyptian coasts and breakwater, through a 
1 study on the force analysis (torque coefficient) and velocity analysis (global entropy

2 generation rate) for different turbine airfoils. To achieve this goal, the CFD technique

3 was used along with an analytical model that investigated the main flow characteristics

4 and estimated the hydrodynamics output power. According to the literature, it is the

5 first time to study the availability of extracted wave energy around Egyptian coast area

6 via a Wells turbine.

\section{2. Mathematical formulations}

8 This section describes the first law analysis method used in this study to measure. In

9 addition, the efficiency calculations for the Wells turbine under sinusoidal-flow

10 conditions were studied using an analytical mathematical model. The net torque which

11 drives the Wells turbine is resultant of the summation of all torques exerted on the

12 turbine as follows:

$13 \quad \sum$ Torque $=T_{\text {aerodynamic }}-T_{\text {Load }}-T_{\text {Loss }}$

$14 \Sigma$ Torque $=\frac{1}{2} \rho\left(V_{a}^{2}+\left(\omega R_{m}\right)^{2}\right) A R_{m} C_{T}-T_{L}-T_{\text {Loss }}$

15 where $T_{L}$ is the load torque

16 By applying the angular moment equation of motion along turbine axis, we get

$$
I \frac{d \omega}{d t}=\sum \text { Torque }
$$

17 where $\boldsymbol{I}$ is the rotor mass moment of inertia and $\omega$ is the angular velocity of the rotor

18 varying with time.

19 Neglecting the torque losses and substituting from eq. (2) into (3) we get: 


$$
I \frac{d \omega}{d t}=\frac{1}{2} \rho\left(V_{a}^{2}+\left(\omega R_{m}\right)^{2}\right) z c b R_{m} C_{T}-T_{L}
$$

1 The load torque can be expressed in a non-dimensional form as:

$$
X_{L}=\frac{T_{L}}{\rho \pi R_{m}^{3} V_{a}^{2}}
$$

2 Hence, the rotor equation of motion is:

$$
\begin{aligned}
& I \frac{d \omega}{d t}=\frac{1}{2} \rho\left(V_{a}^{2}+\left(\omega R_{m}\right)^{2}\right) z c b R_{m} C_{T}-X_{L} \rho \pi R_{m}^{3} V_{a}^{2} \\
& \frac{d \omega}{d t}=\frac{\frac{1}{2} \rho\left(V_{a}^{2}+\left(\omega R_{m}\right)^{2}\right) z c b R_{m} C_{T}-X_{L} \rho \pi R_{m}^{3} V_{a}^{2}}{I} \\
& \int d \omega=\int \frac{\frac{1}{2} \rho\left(V_{a}^{2}+\left(\omega R_{m}\right)^{2}\right) z c b R_{m} C_{T}-X_{L} \rho \pi R_{m}^{3} V_{a}^{2}}{I} d t \\
& \omega_{2}-\omega_{1}=\frac{\frac{1}{2} \rho\left(V_{a}{ }^{2}+\left(\omega R_{m}\right)^{2}\right) z c b R_{m} C_{T}-X_{L} \rho \pi R_{m}^{3} V_{a}^{2}}{I} t_{2}-t_{1}
\end{aligned}
$$

3 For the first law of thermodynamics, the lift and drag coefficient $C_{L}$ and $C_{D}$ are

4 computed from the post processing software. Then, the torque coefficient can be 5 expressed as [51]:

$6 \quad C_{T}=\left(C_{L} \sin \alpha-C_{D} \cos \alpha\right)$

7 The flow coefficint $\phi$ relating tangential and axial velocities of the rotor is difined as:

$8 \quad \phi=\frac{V_{a}}{\omega * R_{m}}$

9 where the $\alpha$ angle of attack is equal to:

$10 \alpha=\tan ^{-1} \frac{V_{a}}{\omega R_{m}}$

11 The mean output power is expressed as:

$$
\text { Output Power }=T_{L} * \omega_{\text {avr }}
$$

12 where $\omega_{\text {avr }}$ is the average velocity during a complete cycle given by: 


$$
\omega_{\text {avr }}=\frac{1}{T} \int_{0}^{T} \omega(t) d t
$$

1 Hence, the output is

$$
\text { Output Power }=X_{L} * \pi * \rho * V_{A m}{ }^{2} * R_{m}{ }^{3} * \omega_{\text {avr }}
$$

2 where $X_{L}$ is the non-dimensional loading torque.

$$
\text { Input power }=\frac{1}{T} \int_{0}^{T} \Delta P * Q d t
$$

3 where $\mathrm{Q}$ is the valume flow rate passing through the rotor area to the turbine and given 4 by:

$$
Q=V_{A} A_{r}
$$

5 The efficiency in the first law of thermodynamics $\left(\mu_{F}\right)$ is defined as:

$6 \quad \mu_{F}=$ mean value of $\frac{\text { Output Power }}{\text { Input Power }}=\frac{\frac{1}{T} \int_{0}^{T} T_{L} \omega(t) d t}{\frac{1}{T} \int_{0}^{T} \Delta P * Q d t}$

7 Figure 1 shows the flow chart that displays the main steps that apply the mathematical

8 model using the MATLAB software. These steps are based on the equations that are

9 derived above, starting from setting the initial angular velocity which causes the initial

10 motion, and operational conditions. The aim is to calculate the generated force on the

11 blade, the instantaneous angular velocity, the output power, and the turbine efficiency.

12 In this work, the rotor geometry data from existing Wells turbine projects (the 13 OSPREY) [52] is used as inlet parameters for the mathematical model. This is in 14 addition to the operating condition data based on the real data from the site, namely, 15 the Southern Mediterranean Basin [50]. 
2 The numerical simulations were conducted with the commercial CFD software ANSYS

3 Fluent .The unsteady Navier-Stokes equations were solved by a finite volume for an

4 incompressible flow and turbulence was modeled using the Large Eddy Simulation.

5 The governing equations employed for Large Eddy Simulation (LES) were obtained by

6 filtering the time-dependent Navier-Stokes equations. The filtering process was chosen

7 as it effectively filters out eddies whose scales are smaller than the filter width or grid

8 spacing used in the computations. The resulting equations, thus, govern the dynamics

9 of large eddies. A filtered variable (denoted by an over-bar) is defined by:

$10 \bar{\phi}(x)=\int_{D} \phi\left(x^{\prime}\right) G\left(x, x^{\prime}\right) d x^{\prime}$

11 where $\mathrm{D}$ is the fluid domain and $\mathrm{G}$ is the filter function that determines the scale of the

12 resolved eddies. In FLUENT, the finite-volume discretization itself implicitly provides

13 the filtering operation [53]:

$14 \bar{\phi}(x)=\frac{1}{V} \int_{V} \phi\left(x^{\prime}\right) d x^{\prime}, x^{\prime} \in V$

15 where $V$ is the volume of a computational cell, the filter function, $\mathrm{G}\left(\mathrm{x}, \mathrm{x}^{\prime}\right)$, implied here 16 is then

$$
G\left(x, x^{\prime}\right)=\left\{\begin{aligned}
1 / V & \text { for } x^{\prime} \in V \\
0 & \text { otherwise }
\end{aligned}\right.
$$

19 The LES model was applied to essentially incompressible (but not necessarily constant-

20 density) flows. Filtering the incompressible Navier-Stokes equations, one obtained [54]

$22 \frac{\partial \rho}{\partial t}+\frac{\partial \rho \bar{u}_{i}}{\partial x_{i}}=0$

$23 \quad \frac{\partial}{\partial t}\left(\rho \bar{u}_{i}\right)+\frac{\partial}{\partial x_{j}}\left(\rho \bar{u}_{i} \bar{u}_{j}\right)=\frac{\partial}{\partial x_{j}}\left(\mu \frac{\partial \bar{u}_{i}}{\partial x_{j}}\right)-\frac{\partial \bar{\rho}}{\partial x_{i}}-\frac{\partial \tau_{i j}}{\partial x_{j}}$ 
$1 \quad$ where $\tau_{i j}$ is the sub-grid-scale stress defined by

$2 \tau_{i j}=\rho \overline{u_{i} u_{j}}-\rho \overline{u_{i}} \overline{u_{j}}$

3 The sub-grid-scale stresses resulting from the filtering operation were unknown, and

4 required modeling. The majority of sub-grid-scale models were eddy viscosity models

5 of the following form:

$6 \quad \tau_{i j}-\frac{1}{3} \tau_{k k} \sigma_{i j}=-2 \mu_{t} \bar{S}_{i j}$

7 where $\bar{S}_{i j}$ is the rate-of-strain tensor for the resolved scale defined by:

$8 \quad \bar{S}_{i j}=\frac{1}{2}\left(\frac{\partial \bar{u}_{i}}{\partial x_{j}}+\frac{\partial \bar{u}_{j}}{\partial x_{i}}\right)$

9 and $\mu_{t}$ is the sub-grid-scale turbulent viscosity, for which the Smagorinsky-Lilly model

10 is used. The most basic of sub-grid-scale models for "Smagorinsky-Lilly model" was

11 proposed by Smagorinsky [55] and further developed by Lilly [56]. In the

12 Smagorinsky-Lilly model, the eddy viscosity is modeled by:

$13 \mu_{t}=\rho L_{s}^{2}|\bar{S}|$

14 where $L_{s}$ is the mixing length for sub-grid-scale models and $|\bar{S}|=\sqrt{2 \bar{S}_{i j} \bar{S}_{i j}}$. The $L_{s}$ is

15 computed using:

$16 L_{s}=\min \left(k d, C_{s} V^{1 / 3}\right)$

17 where $C_{s}$ is the Smagorinsky constant, $k=0.42, d$ is the distance to the closest wall,

18 and $V$ is the volume of the computational cell. Lilly derived a value of 0.23 for $C_{s}$ from

19 homogeneous isotropic turbulence. However, this value was found to cause excessive

20 damping of large-scale fluctuations in the presence of mean shear or in transitional

21 flows. $C_{s}=0.1$ was found to yield the best results for a wide range of flows. 
1 The transport equations of such models can be found in turbulence modeling texts such

2 as [57]. The second law of thermodynamics defines the net-work transfer rate $\dot{W}$ as

3 [58]:

$4 \quad \dot{W}_{\text {rev }}-\dot{W}=T_{o} S_{g e n}$

5 With the use of entropy analysis method, it is possible to express the irreversible

6 entropy generation in terms of the derivatives of local flow quantities in the absence of

7 phase changes and chemical reactions. The two dissipative mechanisms in viscous flow

8 are the strain-originated dissipation and the thermal dissipation, which correspond to a

9 viscous and a thermal entropy generation respectively [59], and can be expressed as:

$10 \quad S_{g e n}=S_{V}+S_{t h}$

11 In incompressible isothermal flow, such as the case in hand, the thermal dissipation

12 term vanishes. The local viscous irreversibilities, therefore, can be expressed as:

$13 \quad S_{V}=\frac{\mu}{T_{o}} \dot{\phi}$

14 where $\dot{\phi}$ is the viscous dissipation term that is expressed in two dimensional Cartesian

15 coordinates as [59]:

$16 \quad \dot{\phi}=2\left[\left(\frac{\partial u}{\partial x}\right)^{2}+\left(\frac{\partial v}{\partial y}\right)^{2}\right]+\left(\frac{\partial u}{\partial y}+\frac{\partial v}{\partial x}\right)^{2}$

17 and the global entropy generation rate is hence expressed as [31]:

$18 \quad S_{G}=\iint_{x y} S_{V} d y d x$

19 and finally, the second law efficiency is defined as [32]:

$20 \quad \eta_{S}=\frac{K E}{\text { Exergy }}$

21 where Exergy $=K E+S_{G}$ and $K E=\frac{1}{2} V^{2}$ 
1 From the above equation, it can be concluded that the increase in torque coefficient

2 leads to an increase in the first law efficiency. On the other hand, the decrease in the

3 global entropy generation rate leads to an increase in the second law efficiency.

\section{3.1. Computational model and boundary conditions}

5 Two-dimensional numerical models for NACA0015 airfoils were built up and validated

6 against experimental measurements under unsteady flow conditions. The

7 computational domain was discretized to Cartesian structured finite volume cells using

8 GAMBIT code. The second order upwind interpolation scheme was used in this work,

9 where its results were approximately similar to those yielded by third order MUSCL

10 scheme in the present situation. In addition, in some cases the third order MUSCL

11 scheme showed high oscillatory residual during the solution.

12 The axial flow of Wells Turbine is modeled as a sinusoidal wave in this simulation.

13 Therefore, inlet boundary conditions are set to change with time. In order to apply the

14 inlet boundary condition, inlet velocity with periodic function (see Figure 2) is 15 generated as follows:

$$
V_{(t)}=V_{o}+V_{A} \sin \left(\sin 2 \pi f t_{\sin }\right)
$$

17 where $t_{\sin }$ is equal to $(4,6$, and 8$)$ seconds and is set as one period in this simulation, 18 considering the real data from the Egyptian coasts. The time step is set as 0.000296721

19 second in order to satisfy CFL (Courant Friedrichs Lewy) condition equal to 1 [60].

20 Furthermore, the sinusoidal wave condition creates various Reynolds numbers up to 2 $21 \times 10^{4}$. 


\section{3.2. Grid sensitivity test (Verification)}

2 In order to ensure that the numerical model is free from numerical diffusion and

3 artificial viscosity errors, several grid numbers were tested to estimate the number of

4 grid cells required to establish a grid-independent solution. Table 1 shows the

5 specifications of different grids used in unsteady two-dimensional models with constant

6 velocity. Figure 3 shows the pressure coefficient distribution on the upper and lower

7 surfaces of the NACA0012 airfoil as computed by the four grids. Grid D required more

8 time than grid $\mathrm{C}$, yielding similar results. Therefore, grid $\mathrm{C}$ was chosen to conduct the 9 analysis presented hereafter.

\section{4. Models validation}

\section{4.1. Validation of the Analytical Model}

12 The experimental data from $[61,62]$ for an unsteady flow was used to validate our

13 analytical mathematical model. The experimental data from a test rig was used by Wave

14 Energy Research Team, University of Limerick. It consisted of a bell mouth entry, test 15 section, drive and transmission section, a plenum chamber with honeycomb section, a 16 calibrated nozzle, and a centrifugal fan. The turbine test section had an internal diameter 17 of $600 \mathrm{~mm}$ and a fabricated rotor of a $598 \mathrm{~mm}$ diameter, leaving a tip clearance of 1 $18 \mathrm{~mm}$. The hub diameter is $358.8 \mathrm{~mm}$, providing a hub to tip ratio of 0.6 and chord length 19 of $120 \mathrm{~mm}$. The turbine was mounted on a shaft in a cylindrical annular duct. The shaft 20 was coupled to motor/generator via a torque meter. The turbine blades ( 8 blades for 21 solidity $=0.64$ and 6 blades for solidity $=0.48$ ) were set on the hub at a $90^{\circ}$ angle of 22 stagger along the $y$-axis. Figure 4 shows a good agreement between the mean efficiency 
1 from reference [61, 62] with $t_{\sin }$ equal to $9.2 \mathrm{sec}$, and the predicted mean efficiency

2 from the mathematical code at same $t_{\text {sin }}$.

\section{4.2. Validation of the CFD model}

4 Large Eddy Simulation model was used to model the flow around NACA0015 airfoil

5 in order to give the best agreement with experimental data adopted from [63-65]. The

6 Eddy model proved effective, where the data was used to simulate and validate the CFD

7 model as it had a suitable Reynolds number equal to $2 \times 10^{4}$, and where the torque

8 coefficient result was clear. The validation case details for Wells turbine prototype are

9 characterized by the following parameters: hub radius, is equal to $101 \mathrm{~mm}$; tip radius,

10 equal to $155 \mathrm{~mm}$; NACA0015 blade profile with constant chord length, equal to 74

$11 \mathrm{~mm}$; and a number of blades, equal to 7. Therefore, the hub-to-tip ratio and the solidity

12 are equal to 0.65 and 0.64 , respectively. The blades were produced with composite

13 material reinforced by carbon fiber with suitable attachment. The experimental data

14 was at steady flow conditions. Therefore, the average value for the lift and drag

15 coefficient was used to calculate one value for the torque coefficient for each angle of

16 attack. Figure 5 displays the result of using the computational model under sinusoidal

17 inlet flow velocity with experimental data from [63-65]. A very good agreement was 18 achieved. 


\section{5. Results and Discussion}

2 The CFD models were used, the results of which simulated the compression cycle with

3 accelerating and decelerating flow. Otherwise, the wave cycle with the compression

4 and suction stage was used in the analytical method.

\section{$5 \quad$ 5.1. First law of thermodynamics analysis}

6 The comparison between the torque coefficient for accelerating and decelerating flow

7 with four different airfoils was shown in Figure 6. It can be noted that the sinusoidal

8 wave with $t_{\sin }$ of $4 \mathrm{sec}$ has a large torque coefficient. Moreover, the torque coefficient

9 value at decelerating flow is always higher than that at accelerating flow, except

10 NACA0015 for sinusoidal wave with 6 sec. In addition, the sinusoidal wave with $8 \mathrm{sec}$

11 has the smallest difference in torque coefficient values between accelerating and

12 decelerating flow as show in Table 2.

13 To understand the reasons why the torque coefficient at decelerating flow is mostly

14 higher than that at accelerating flow, the contours and path line of velocity around the 15 blade were investigated. Figures 7 and 8 show the contours and path line of velocity 16 magnitude around the NACA0020 airfoil blade at the same instantaneous velocity $(2.08$ $17 \mathrm{~m} / \mathrm{s}$ ). It can be shown that at an accelerating flow, the airfoil has very low velocities 18 (see Figure 7) and a high separation layer (see Figure 8) at the trailing edge area than 19 that in a decelerating flow condition. This difference between the accelerating and the 20 decelerating flow decreases, with an increase in $t_{\text {sin }}$ for the sinusoidal wave.

21 Figures 9 and 10 show the pressure distribution around the upper and lower surface of 22 NACA0020, at accelerating and decelerating flow, and at velocity equal to $2.09 \mathrm{~m} / \mathrm{s}$ 23 with different time periods. The difference between the pressure value at upper and 24 lower surface has a direct effect on the torque coefficient value, whereby, this difference 
1 at decelerating flow was lower than that at accelerating flow except $t_{\sin }$ with $8 \mathrm{sec}$. This

2 behaviour is the same as that of the torque coefficient value. When comparing between

3 the accelerating and decelerating flow, it can be noted that the decelerating flow has a

4 negative pressure value. Furthermore, the increase in time period is accompanied by a

5 decrease in pressure value at accelerating flow. On the other hand, the increase in time

6 period is accompanied by an increase in pressure value at decelerating flow. The low-

7 pressure area was shown around the trailing edge, and increased with the increase of

8 time period.

9 The total average torque coefficient during the cycle for four different airfoils at 10 different time periods was shown in Figure 11. It can be concluded that the sinusoidal 11 wave, with $t_{\sin }$ equal to $4 \mathrm{sec}$, has the highest torque coefficient, where, NACA0020 12 (with $t_{\sin }$ equal to $4 \mathrm{sec}$ ) gives a torque coefficient higher than NACA0012 by 13\%, 13 NACA0015 by $5 \%$ and NACA0021 by $2 \%$. For the sinusoidal wave with $t_{\sin }$ of $6 \mathrm{sec}$, 14 the airfoil NACA0012 gives a torque coefficient higher than NACA0015 by 4\%, but it 15 was approximately the same as NACA0020, with an increase of only $0.6 \%$. Also, 16 NACA0012 gives a torque coefficient that is $6 \%$ higher than NACA0021. Finally, for 17 the sinusoidal wave with $t_{\sin }$ equal to $8 \mathrm{sec}$, the NACA0012 gives a torque coefficient 18 higher than NACA0015 by $7 \%$, NACA0020 by $18 \%$ and NACA0021 by $17 \%$.

19 Figure 12 shows the instantaneous torque coefficient at a compression cycle for different airfoils (NACA0012, NACA0015, NACA0020 and NACA0021) with

21 different time periods ( $4 \mathrm{sec}, 6 \mathrm{sec}$ and $8 \mathrm{sec}$ ). It can be seen that in the first half of each 22 cycle (accelerating flow), NACA0012 always has a higher torque coefficient. The 23 comparison between the maximum torque coefficient values for each time period cycle 24 was shown in Figure 13. The NACA0012 airfoil section has the highest value at 
1 sinusoidal wave cycles with $t_{\sin }$ equal to $6 \mathrm{sec}$ and with $t_{\sin }$ equal to $8 \mathrm{sec}$. On the other

2 hand, the NACA0020 airfoil section has the highest value at the sinusoidal wave cycle

3 with $t_{\sin }$ equal to $4 \mathrm{sec}$. In addition, the NACA0020 airfoil section (with $t_{\sin }$ equal to

$44 \mathrm{sec}$ ) creates a torque coefficient more than NACA0012 (with $t_{\text {sin }}$ equal to $8 \mathrm{sec}$ ) by

$554 \%$, NACA0012 (with $t_{\sin }$ equal to $6 \mathrm{sec}$ ) by 44\%, and NACA0012 (with $t_{\sin }$ equal

6 to $4 \mathrm{sec})$ by $13 \%$.

7 Figure 14 highlights the effect of the low velocity area and separation layer at trailing

8 edge by velocity contours and path line around the NACA0012 airfoil at a maximum

9 velocity of $2.92 \mathrm{~m} / \mathrm{s}$. It is clear that the torque coefficient is influenced by the low

10 velocity area and separation layer at trailing edge. When the low velocity area at trailing

11 edge increases, the torque coefficient value decreases. Similarly, as the separation layer

12 at trailing edge increases, the torque coefficient value also decreases. The pressure

13 distribution around the upper and lower surface of airfoil at accelerating and

14 decelerating flow was shown in Figure 15 at a maximum velocity of $(2.92 \mathrm{~m} / \mathrm{s})$, with

15 different time periods (4, 6 and $8 \mathrm{sec})$. The higher disturbances occurring in separation

16 layers at the upper surface than those occurring at the lower surface (Figure 14) is due

17 to the irregular values of pressure at the upper surface. The low pressure areas around

18 the trailing edge increase the separation layer at the trailing edge; therefore, the

19 separation layers at a 4 second time period have lowest disturbances and lowest low-

20 pressure areas around the trailing edge. Table 3 summarizes the torque coefficient at

21 different time periods ( $t_{\sin }$ equal to $4 \mathrm{sec}, 6 \mathrm{sec}$ and $8 \mathrm{sec}$ ) for the four airfoils

22 (NACA0012, NACA0015, NACA0020 and NACA0021). 


\section{$1 \quad$ 5.2. Second law of thermodynamics analysis}

2 Figure 16 highlights the comparison between the global entropy generation rate for

3 accelerating and decelerating flows for the four different airfoils. All airfoils in the

4 accelerating flow create global entropy generation rate lower than that created in the

5 decelerating flow. The difference in the global entropy generation rate between the

6 accelerating and decelerating flows is not influenced by the change in time period (see

7 Table 4). As an average for all airfoils, the sinusoidal wave cycle with $t_{\sin }$ of $8 \mathrm{sec}$ has

8 the lowest difference in $S_{G}$ between accelerating and decelerating flows for the four

9 different airfoils.

10 The contours of global entropy generation rate around the NACA0021 at the

11 instantaneous velocity $(2.08 \mathrm{~m} / \mathrm{s})$ for the accelerating and decelerating flow were

12 represented in Figure 17. It can be seen that the global entropy generation rate around 13 the airfoil section in the decelerating flow was higher than that in the accelerating flow

14 at the three different time periods (as noted above in Figure 16). The average value of 15 the global entropy generation rate for each airfoil during the sinusoidal cycle with three 16 different time periods was shown in Figure 18. It can be concluded that the NACA0015

17 has the lowest value of the global entropy generation rate at the three different time 18 periods ( $4 \mathrm{sec}, 6 \mathrm{sec}$ and $8 \mathrm{sec}$ ), when it was compared with other airfoils (NACA0012, 19 NACA0020 and NACA0021). See Table 5 for more details.

20 Figure 19 shows the contours of the global entropy generation rate at a maximum 21 velocity $(2.92 \mathrm{~m} / \mathrm{s})$ around NACA0015 airfoil with three different time periods. It can 22 be seen that NACA0015 at sinusoidal wave with $t_{\sin }$ equal to $8 \mathrm{sec}$ has a lower global 23 entropy generation rate than other time periods for the same airfoil (NACA0015) and 24 same velocity $(2.92 \mathrm{~m} / \mathrm{s})$. Hence, Figure 20 compares between the values of $\mathrm{S}_{\mathrm{G}}$ (Figure 
$120, \mathrm{~A}$ ) and $\mu_{S}$ (Figure 20, B) for NACA0015 at three different time periods. It can be

2 concluded that the NACA0015 (with $t_{\sin }$ equal to $8 \mathrm{sec}$ ) has lower $\mathrm{S}_{\mathrm{G}}$ than NACA0015

3 (with $t_{\sin }$ equal to $6 \mathrm{sec}$ ) by $-6 \%$ and NACA0015 (with $t_{\sin }$ equal to $4 \mathrm{sec}$ ) by $-3 \%$. In

4 addition, the $\mu_{S}$ of NACA0015 (with $t_{\sin }$ equal to $8 \mathrm{sec}$ ) is higher than NACA0015

5 (with $t_{\sin }$ equal to $6 \mathrm{sec}$ ) by $1 \%$ and NACA0015 (with $t_{\sin }$ equal to $4 \mathrm{sec}$ ) by $2 \%$. Table

66 summarizes the global entropy generation rate values at different time periods $\left(t_{\sin }\right.$

7 equal to $4 \mathrm{sec}, 6 \mathrm{sec}$ and $8 \mathrm{sec}$ ) for the four airfoils (NACA0012, NACA0015,

8 NACA0020 and NACA0021).

\section{5.3. Analytical analysis}

10 To examine the effect of wave time period (operating parameter), as well as solidity

11 and airfoil section (design parameters) on the starting and running characteristics, a

12 mathematical analysis was used. It is also used to estimate the turbine efficiency and

13 the output power. The mathematical model gives the relationship of rotor angular

14 velocity with time as a curve in Figure 21, where the figure shows the NACA0012

15 airfoil at a time period equal to $6 \mathrm{sec}$ with solidity equal to 0.64 in free running condition

16 and with different loading torque coefficients. Furthermore, it can be noted that the

17 rotor angular velocity was oscillating around a certain average value due to the

18 oscillating inlet velocity.

19 Figure 22 represents starting and running characteristics by change in specific 20 parameters, such as time period, solidity and airfoil section. It can be noted that the 21 crawling condition appears at the starting period for the sinusoidal wave cycle with $t_{\sin }$ 22 equal to $4 \mathrm{sec}$ (Figure $22 \mathrm{~A}$ ). Otherwise, the three different time periods give the same 23 average velocity $(51.6 \mathrm{rad} / \mathrm{s})$ after the starting period. According to Figure $22 \mathrm{~B}$ the 24 change in solidity from 0.64 to 0.8 does not have an effect (approximately) on the 
1 starting and running characteristics. On the other hand, the NACA0015 airfoil section

2 has the same starting characteristics of NACA0012 but lower rotor average velocity 3 (45.9 rad/s) than NACA0012, see Figure $22 \mathrm{C}$.

4 The mean turbine efficiency under sinusoidal flow conditions with different operating 5 and design parameters was shown in Figure 23. It can be noted that the peak efficiency 6 of the turbine which has sinusoidal wave with $t_{\sin }$ equal to $4 \mathrm{sec}$ is higher than that with $76 \mathrm{sec}$ and $8 \mathrm{sec}$ by $8 \%$, as shown in Figure 23 A. It can also be noted that the turbine 8 which has sinusoidal wave with $t_{\sin }$ equal to $4 \mathrm{sec}$ works with a higher flow coefficient 9 than that with $6 \mathrm{sec}$ and $8 \mathrm{sec}$ by $17 \%$. Figure $23 \mathrm{~B}$ shows that the increase in turbine 10 solidity from 0.64 to 0.8 decreases the peak efficiency by $1 \%$ and does not have an 11 effect on the flow coefficient. On the other hand, the change in the airfoil section of a 12 turbine from NACA0012 to NACA0015 does not have an effect on the peak efficiency. 13 However, the turbine with NACA0015 airfoil section works with a higher flow 14 coefficient by $15 \%$ than that with NACA0012 airfoil section.

15 Figure 24 presents the net output power for the Wells turbine under different operating 16 and design parameters based on the real data from the Egyptian northern coast. It can 17 be concluded that the operating condition inlet flow with $6 \mathrm{sec}$ time period gives a 18 maximum output power that is higher than $4 \mathrm{sec}$ by $19 \%$, and $8 \mathrm{sec}$ by $1 \%$, see Figure $1924 \mathrm{~A}$. In addition, the change in the design parameters had an effect on the output power 20 value. So, the increase in solidity from 0.64 to 0.8 came with an increase in the net 21 output power by $18 \%$ (Figure $24 \mathrm{~B}$ ). Moreover, Figure $24 \mathrm{C}$ shows that the Wells 22 turbine with NACA0012 airfoil section has a higher net output power than that with 23 NACA0015 airfoil section by $31 \%$. These values were generated from one turbine 24 without any attached guide vans or other enhanced performances, but in the real station, 25 the number of turbine reached two turbines such as the Prototype OWC device (biplane) 
1 [66] and LIMPET [67-72] (contra-rotating) in Scotland. Furthermore, the number of

2 turbines can reach four as in the OSPREY [52] used in Scotland or sixteen turbines

3 such as in Mutriku Wave Energy Plant $[73,74]$ in Spain. In addition, the guide vans

4 can be attached to increase the turbine performance such as Mighty Whale [75] in Japan

5 and The Pico Power Plant [76-81] in Portugal.

\section{6. Conclusion}

7 The performance of Wells turbine was investigated by the aerodynamic force (i.e. first

8 law) efficiency as well as the entropy (i.e. second law) efficiency under oscillating flow

9 conditions. The work was performed by using time-dependent CFD models of different

10 NACA airfoils under sinusoidal flow boundary conditions. Besides, an analytical

11 analysis was used to study the starting and running characteristics under sinusoidal flow

12 conditions with different operating and design parameters. Furthermore, the turbine

13 efficiency curve and the net output power were estimated. From the comparison

14 between the maximum torque coefficient values for each time period cycle it can be

15 concluded that the generating torque coefficient on the NACA0020 airfoil section (with

$16 t_{\sin }$ equal to $4 \mathrm{sec}$ ) was higher than NACA0012 (with $t_{\sin }$ equal to $8 \mathrm{sec}$ ) by $54 \%$,

17 NACA0012 (with $t_{\sin }$ equal to $6 \mathrm{sec}$ ) by $44 \%$ and NACA0012 (with $t_{\sin }$ equal to $4 \mathrm{sec}$ )

18 by $13 \%$. Moreover, NACA0015 had shown a decrease in the value of $\mathrm{S}_{\mathrm{G}}$ at the three

19 different $t_{\sin }(4 \mathrm{sec}, 6 \mathrm{sec}$ and $8 \mathrm{sec})$ by $-14 \%,-10.3 \%$ and $-14.7 \%$, respectively as an

20 average value. On the other hand, for NACA0015, the lowest $\mathrm{S}_{\mathrm{G}}$ was generated when

$21 t_{\sin }$ was equal to $8 \mathrm{sec}$ with an average of $-4.5 \%$ less $S_{G}$ than that of $t_{\sin }$ equal to 4 and

226 sec. $2.2 \mathrm{~kW}$ was the maximum output power value that can be achieved by Wells

23 turbine with NACA0012 airfoil section and solidity equal to 0.8 , under sinusoidal wave

24 with $t_{\sin }$ equal to $6 \mathrm{sec}$. 
1 Future research should focus on design optimization to create an optimum design,

2 which has a maximum torque coefficient, a minimum entropy generation, in addition

3 to the highest output power value. Furthermore, the study recommends the use of wave

4 energy in Egypt as a way to cut down on excessive high fossil fuel usage.

\section{Acknowledgements}

6 The authors would like to acknowledge the support provided by the Department of 7 Naval Architecture, Ocean and Marine Engineering at Strathclyde University, UK and 8 the Department of Marine Engineering at the Arab Academy for Science, Technology 9 and Maritime Transport, Egypt.

\section{References}

[1] A.V.d. Rosa, Fundamentals of Renewable Energy Processes, Third Edition ed., Elsevier Academic Press, United States of America, 2012.

[2] A.F.d.O. Falcão, Wave energy utilization: A review of the technologies, Renewable and Sustainable Energy Reviews, 14 (2010) 899-918.

[3] J. Twidell, T. Weir, Renewable Energy Resources, Second edition ed., Taylor \& Francis, New York, USA, 2006.

[4] A.S. Shehata, Q. Xiao, K.M. Saqr, D. Alexander, Wells turbine for wave energy conversion: a review, INTERNATIONAL JOURNAL OF ENERGY RESEARCH, (2016).

[5] F.A.M. T. J. T. Whittaker, Design Optimisation of Axisymmetric Tail Tube Buoys, in: IUTAM, Symposium on Hydrodynamics of Ocean Wave Energy Conversion, Lisbon,July., 1985.

[6] T.J.J. Whittaker, Mcllwain, S. T. and Raghunathan, S. , Islay Shore Line Wave Power Station, Proceedings European Wave Energy Symposium., Paper G6, Edinburgh. (1993).

[7] S. Raghunathan, Theory and Performance of Wells Turbine, Queen's University of Belfast, Rept. WE/80/13R (1980).

[8] S. Raghunathan, The Wells Air Turbine for Wave Energy Conversion, Progress Aerospace Sciences, 31 (1995) 335-386.

[9] T. Ghisu, P. Puddu, F. Cambuli, Numerical analysis of a wells turbine at different nondimensional piston frequencies, Journal of Thermal Science, 24 (2015) 535-543.

[10] R. Curran, M. Folley Air turbine design for OWCs, in: i.J. Cruz (Ed.) Ocean Wave Energy, Springer, Berlin. , 2008, pp. 189-219.

[11] A.F.O. Falcão, L.M.C. Gato, Air Turbines, in: A.A. Sayigh (Ed.) Comprehensive Renewable Energy Ocean Energy, Elsevier,Oxford . 2012, pp. 111-149.

[12] R. Starzmann, Aero-acoustic Analysis of Wells Turbines for Ocean Wave Energy Conversion, in, Universitat Siegen, Germany, 2012.

[13] T. Setoguchi, M. Takao, Current status of self rectifying air turbines for wave energy conversion, Energy Conversion and Management, 47 (2006) 2382-2396. 
[14] S. Raghunathan, W.C. Beattie, Aerodynamic performance of contra-rotating Wells turbine for wave energy conversion, ARCHIVE: Proceedings of the Institution of Mechanical Engineers, Part A: Journal of Power and Energy 1990-1996 (vols 204-210), 210 (1996) 431-447.

[15] R. Curran, T.J.T. Whittaker, S. Raghunathan, W.C. Beattie, Performance Prediction of Contrarotating Wells Turbines for Wave Energy Converter Design, Journal of Energy Engineering, 124 (1998) 35-53.

7 [16] L.M.C. Gato, R. Curran, The Energy Conversion Performance of Several Types of Wells 8 Turbine Designs, Proceedings of the Institution of Mechanical Engineers, Part A: Journal of 9 Power and Energy, 211 (1997) 133-145.

10 [17] M. Mamun, Y. Kinoue, T. Setoguchi, K. Kaneko, A.K.M.S. Islam, Improvement af the 11 Performance of the Wells Turbine by using a Very Thin Elongated Endplate at the Blade Tip, Bangladesh, 2006.

[18] M. Takao, T. Setoguchi, Y. Kinoue, K. Kaneko, Wells Turbine with End Plates for Wave Energy Conversion, Ocean Engineering, 34 (2007) 1790-1795.

[19] T.H. Kim, T. Setoguchi, K. Kaneko, S. Raghunathan, Numerical investigation on the effect of blade sweep on the performance of Wells turbine, Renewable Energy, 25 (2002) 235-248.

[20] T. Setoguchi, M. Takao, K. Itakura, M. Mohammad, K. Kaneko, A. Thakker, Effect of Rotor Geometry on the Performance of Wells Turbine, in: The Thirteenth International Offshore and Polar Engineering Conference, The International Society of Offshore and Polar Engineers, Honolulu, Hawaii, USA, 2003, pp. 374-381.

[21] M. Inoue, Kaneko, K, Setoguchi T, and Hamakawa, H Air turbine with self-pitch-controlled blades for wave power generator (Estimation of performances by model testing), JSME International Journal, Ser II, 32 (1989) 19-24.

[22] S. Salter, Variable Pitch Air Turbines," Proc Euro Wave Energy Symp, Edinburgh, pp 435442., in: Symposium of European Wave Energy, Edinburgh, 1993, pp. 435-442.

[23] G.L. Sarmento AJNA, and FalcZo AfdeO Wave-Energy Absorption by an OWC Device with Blade-Pitch-Controlled Air-Turbine, Proc 6th Int Offshore Mechanics and Arctic Eng Symp, ASME, 2 (1987) 465-473.

[24] T. Setoguchi, Raghunathan, S, Takao, M, and Kaneko, K, Air-Turbine with Self-PitchControlled Blades for Wave Energy Conversion (Estimation of Performances in Periodically Oscillating Flow), Int Journal Rotating Machinery, 3 (1997) 233-238.

[25] M. Takao, Setoguchi, T, Kaneko, K, and Inoue, M, Air Turbine with Self-Pitch-Controlled Blades for Wave Energy Conversion, Int Journal Ofihore and Polar Eng, ISOPE, 7 (1997) 308312.

[26] M. Takao, Setoguchi, T, Santhaknmar, S, and Kaneko, K, A Comparative Study of Turbines Using Pitch-Controlled Blades for Wave Energy Conversion, in: Proc 2nd Int Symp Fluid Mechanics and Heat Transfer, Dhaka, 1997, pp. 243-250.

[27] S.A. Vakalis IS, Real-time control of OWC with a variable pitch-angle turbine, in: Proceedings of the Fourth European Wave Energy Conference, Denmark, 2000, pp. 309-318.

[28] F.P. Thakker T, Bajeet ES. , CA9: analysis of a stall-resistant aerofoil in view of wave power conversion, in: Proceedings of the 11th International Offshore and Polar Engineering Conference, Stavanger, Norway, 2001, pp. 614-623.

[29] M.H. Mohamed, G. Janiga, E. Pap, D. Thévenin, Multi-objective Optimization of the Airfoil Shape of Wells Turbine used for Wave Energy Conversion, Energy, 36 (2011) 438-446.

[30] S. Shaaban, Insight Analysis of Biplane Wells Turbine Performance, Energy Conversion and Management, 59 (2012) 50-57.

[31] A.S. Shehata, K.M. Saqr, M. Shehadeh, Q. Xiao, A.H. Day, Entropy Generation Due to Viscous Dissipation around a Wells Turbine Blade: A Preliminary Numerical Study, Energy Procedia, 50 (2014) 808-816. 
[32] A.S. Shehata, K.M. Saqr, Q. Xiao, M.F. Shehadeh, A. Day, Performance Analysis of Wells Turbine Blades Using the Entropy Generation Minimization Method, Renewable Energy 86 , 1133-1123 (2016).

[33] R. Soltanmohamadi, E. Lakzian, Improved design of Wells turbine for wave energy conversion using entropy generation, Meccanica, Springer Netherlands., (2015) 1-10.

[34] K. Pope, I. Dincer, G.F. Naterer, Energy and Exergy Efficiency Comparison of Horizontal and Vertical Axis Wind Turbines, Renewable Energy, 35 (2010) 2102-2113.

8 [35] O. Baskut, O. Ozgener, L. Ozgener, Effects of Meteorological Variables on Exergetic 9 Efficiency of Wind Turbine Power Plants, Renewable and Sustainable Energy Reviews, 14 10 (2010) 3237-3241.

11 [36] A.M. Redha, I. Dincer, M. Gadalla, Thermodynamic Performance Assessment of Wind 12 Energy Systems: An Application, Energy, 36 (2011) 4002-4010.

[37] O. Ozgener, L. Ozgener, Exergy and Reliability Analysis of Wind Turbine Systems: A Case Study, Renewable and Sustainable Energy Reviews, 11 (2007) 1811-1826.

[38] O. Baskut, O. Ozgener, L. Ozgener, Second Law Analysis of Wind Turbine Power Plants: Cesme, Izmir Example, Energy, 36 (2011) 2535-2542.

[39] S.M. Mortazavi, M.R. Soltani, H. Motieyan, A Pareto optimal multi-objective optimization for a horizontal axis wind turbine blade airfoil sections utilizing exergy analysis and neural networks, Journal of Wind Engineering and Industrial Aerodynamics, 136 (2015) 62-72.

[40] Y. Şöhret, E. Açıkkalp, A. Hepbasli, T.H. Karakoc, Advanced exergy analysis of an aircraft gas turbine engine: Splitting exergy destructions into parts, Energy, 90 (2015) 1219-1228.

[41] M. Ghazikhani, I. Khazaee, E. Abdekhodaie, Exergy analysis of gas turbine with air bottoming cycle, Energy, 72 (2014) 599-607.

[42] D.-C. Sue, C.-C. Chuang, Engineering design and exergy analyses for combustion gas turbine based power generation system, Energy, 29 (2004) 1183-1205.

[43] A.M. Alklaibi, M.N. Khan, W.A. Khan, Thermodynamic analysis of gas turbine with air bottoming cycle, Energy, 107 (2016) 603-611.

[44] C.T. Yucer, Thermodynamic analysis of the part load performance for a small scale gas turbine jet engine by using exergy analysis method, Energy, 111 (2016) 251-259.

[45] M.H. Mohamed, S. Shaaban, Numerical Optimization of Axial Turbine with Self-pitchcontrolled Blades used for Wave Energy Conversion, International Journal of Energy Research, 38 (2014) 592-601.

[46] M.H. Mohamed, S. Shaaban, Optimization of Blade Pitch Angle of an Axial Turbine Used for Wave Energy Conversion, Energy, 56 (2013) 229-239.

[47] G. Mørk, S. Barstow, A. Kabuth, M.T. Pontes, ASSESSING THE GLOBAL WAVE ENERGY POTENTIAL, in: 29th International Conference on Ocean, Offshore Mechanics and Arctic Engineering, ASME, Shanghai, China, 2010.

[48] S. Barstow, G. Mørk, L. Lønseth, J.P. Mathisen, WorldWaves wave energy resource assessments from the deep ocean to the coast, in: The 8th European Wave and Tidal Energy Conference, Proceedings of the 8th European Wave and Tidal Energy Conference, Uppsala, Sweden, 2009.

[49] G. Zodiatis, G. Galanis, A. Nikolaidis, C. Kalogeri, D. Hayes, G.C. Georgiou, P.C. Chu, G. Kallos, Wave energy potential in the Eastern Mediterranean Levantine Basin. An integrated 10-year study, Renewable Energy, 69 (2014) 311-323.

[50] B. Ayat, Wave power atlas of Eastern Mediterranean and Aegean Seas, Energy, 54 (2013) 251-262.

[51] R.E. Sheldahl, P.C. Klimas, Aerodynamic Characteristics of Seven Symmetrical Airfoil Sections Through 180-Degree Angle of Attack for Use in Aerodynamic Analysis of Vertical Axis Wind Turbines, in: Sandia National Laboratories energy report, the United States of America, 1981, pp. 118. 
[52] T.W. Thorpe, An Assessment of The Art OSPREY Wave Energy Device, ETSU-R-90, Dti, in, 1995.

[53] M. Mamun, The Study on the Hysteretic Characteristics of the Wells Turbine in a Deep Stall Condition, in: Energy and Material Science Graduate School of Science and Engineering, Saga University, Japan, 2006, pp. 141.

[54] S. DAHLSTROM, LARGE EDDY SIMULATION OF THE FLOW AROUND A HIGH-LIFT AIRFOIL,

in: Department of Thermo and Fluid Dynamics, CHALMERS UNIVERSITY OF TECHNOLOGY, Goteborg, Sweden, 2003, pp. 62.

[55] J.O. Hinze, Turbulence, McGraw-Hill Publishing Co., New York, 1975.

[56] B.E. Launder, D.B. Spalding, Lectures in Mathematical Models of Turbulence, Academic Press, London, England, 1972.

[57] C. Hirsch, Numerical Computation of Internal and External Flows: The Fundamentals of Computational Fluid Dynamics, Elsevier Science, 2007.

[58] A. Bejan, Entropy Generation Minimization- The New Thermodynamics of Finite-Size Devices and Finite-Time Processes, Applied Physics Reviews, 79 (1996) 1191-1218.

[59] C.L. Iandoli, 3-D Numerical Calculation of the Local Entropy Generation Rates in a Radial Compressor Stage, International journal of thermodynamics, 8 (2005) 83-94.

[60] C.A.K. DE Moura, Carlos S., The Courant-Friedrichs-Lewy (CFL) Condition: 80 Years After Its Discovery, 1 ed., Birkhäuser Basel, Boston, 2013.

[61] A. Thakker, R. Abdulhadi, Effect of Blade Profile on the Performance of Wells Turbine under Unidirectional Sinusoidal and Real Sea Flow Conditions, International Journal of Rotating Machinery, 2007 (2007) 1-9.

[62] A. Thakker, R. Abdulhadi, The Performance of Wells Turbine Under Bi-Directional Airflow, Renewable Energy, 33 (2008) 2467-2474.

[63] M. Torresi, S.M. Camporeale, G. Pascazio, Detailed CFD Analysis of the Steady Flow in a Wells Turbine Under Incipient and Deep Stall Conditions, Journal of Fluids Engineering, 131 (2009) 071103.

[64] M. Torresi, S. Camporeale, G. Pascazio, Performance of a Small Prototype of a High Solidity Wells Turbine, in: Seventh European Conference on Turbomachinery Fluid Dynamics and Thermodynamics, Athens, Greece 2007.

[65] M. Torresi, S. Camporeale, G. Pascazio, Experimental and Numerical Investigation on the Performance of a Wells Turbine Prototype, in: Seventh European Wave and Tidal Energy Conference, Porto, Portugal 2007.

[66] Raghunathan S., Curran R., a.W.T.J. T., Performance of the Islay Wells air turbine, the Institution of Mechanical Engineers, Part A: Journal of Power and Energy, 209 (1995) 55-62.

[67] C.B. Boake, T.J.T. Whittaker, M. Folley, H. Ellen, Overview and Initial Operational Experience of the LIMPET Wave Energy Plant, in: The Twelfth International Offshore and Polar Engineering Conference, The International Society of Offshore and Polar Engineers, Kitakyushu, Japan, 2002, pp. 586-594.

40 [68] T.J.T.M. Whittaker, S.J. \& Raghunathan, S, A review of the Islay shoreline wave power 41 station, in: Proceedings of European Wave Energy Symposium, Edinburgh, Scotland, 1993, 42 pp. 283-286.

[69] T. Heath, Islay LIMPET project monitoring, ETSU V/06/00180/00/Rep, Dti Pup URN No 02/1435., in, 2002.

[70] Wavegen, Research into the further development of the LIMPET shoreline wave energy plant, Dti, V/06/00183/00/Rep, in, 2002.

[71] T. Heath, Whittaker, T.J.T \& Boake, C.B., The design, construction and operation of the LIMPET wave energy converter, in: O.I.a.I. S (Ed.) the 4th European Wave Energy Conference, Danish Technological Institute, Denmark, Aalborg, Denmark., 2000, pp. 49-55.

51 III, CORDIS, JOR3-CT98-0312, in, 2002. 
[73] H. TV, The development of a turbo-generation system for application in OWC 2 breakwaters, in: F. AFO (Ed.) Proceedings of the 7th European Wave Tidal Energy Conference., 3 Porto, Portugal., 2007.

4 [74] Y. Torre-Enciso, I. Ortubia, L.I.L.d. Aguileta, J. Marqués, Mutriku Wave Power Plant: from 5 the thinking out to the reality, in: Proceedings of The 8th European Wave and Tidal Energy 6 Conference, Uppsala, Sweden, 2009, pp. 319-329.

7 [75] Y. Washio, H. Osawa, F.F. Y. Nagata, T.F. H. Furuyama, The offshore floating type wave 8 power device 'Mighty Whale': Open sea tests, in: C. JS (Ed.) proceedings of the 10th 9 International Offshore Polar Engineering Conference, Mountain View, CA, USA, Seattle, WA, 10 USA., 2000, pp. 373-380.

11 [76] A.F.d.S. Falcao, M.; Whittaker, T.J.T. \& Lewis, A.W., Design of a shoreline wave power 12 plant for the island of Pico, Azores, in: Proceedings of the 2nd European Wave Power 13 Conference, 1995.

14 [77] A.F.d. Falcao, The shoreline OWC wave power plant at the Azores, in: Proceedings of 4th 15 European Wave Energy Conference, Denmark, 2000, pp. 42-47.

16 [78] A.F.d.O.J. Falcao, P.A.P., OWC wave energy devices with air flow control, Ocean 17 Engineering, 26 (1999) 1275-1295.

18 [79] A.F.d. Falcao, Control of an oscillating-water-column wave power plant for maximum 19 energy production, Applied Ocean Research, 24 (2003) 73-82.

20 [80] A.F.d. Falcao, Stochastic Modelling in wave power-equipment optimisation: maximum 21 energy production versus maximum profit, Ocean Engineering, 31 (2004) 1407-1421.

22 [81] A.F.d. Falcao, Control of an oscillating-water-column wave power plant for maximum energy production, in: Applied Ocean Research 24, 2002, pp. 73-82. 


\section{Highlights:}

2

3

4

5

6

7

8

9

10

11

12

13
- The wave energy in Egypt is the way to reduce fossil fuel usage.

- First and second law analyses of flow features around the blade were presented.

- The running and starting characteristics have been investigated using analytical code.

- NACA0015 airfoil always gives global entropy generation rate less than other airfoils.

- The effect of operating and design parameters on the output power value was discussed. 


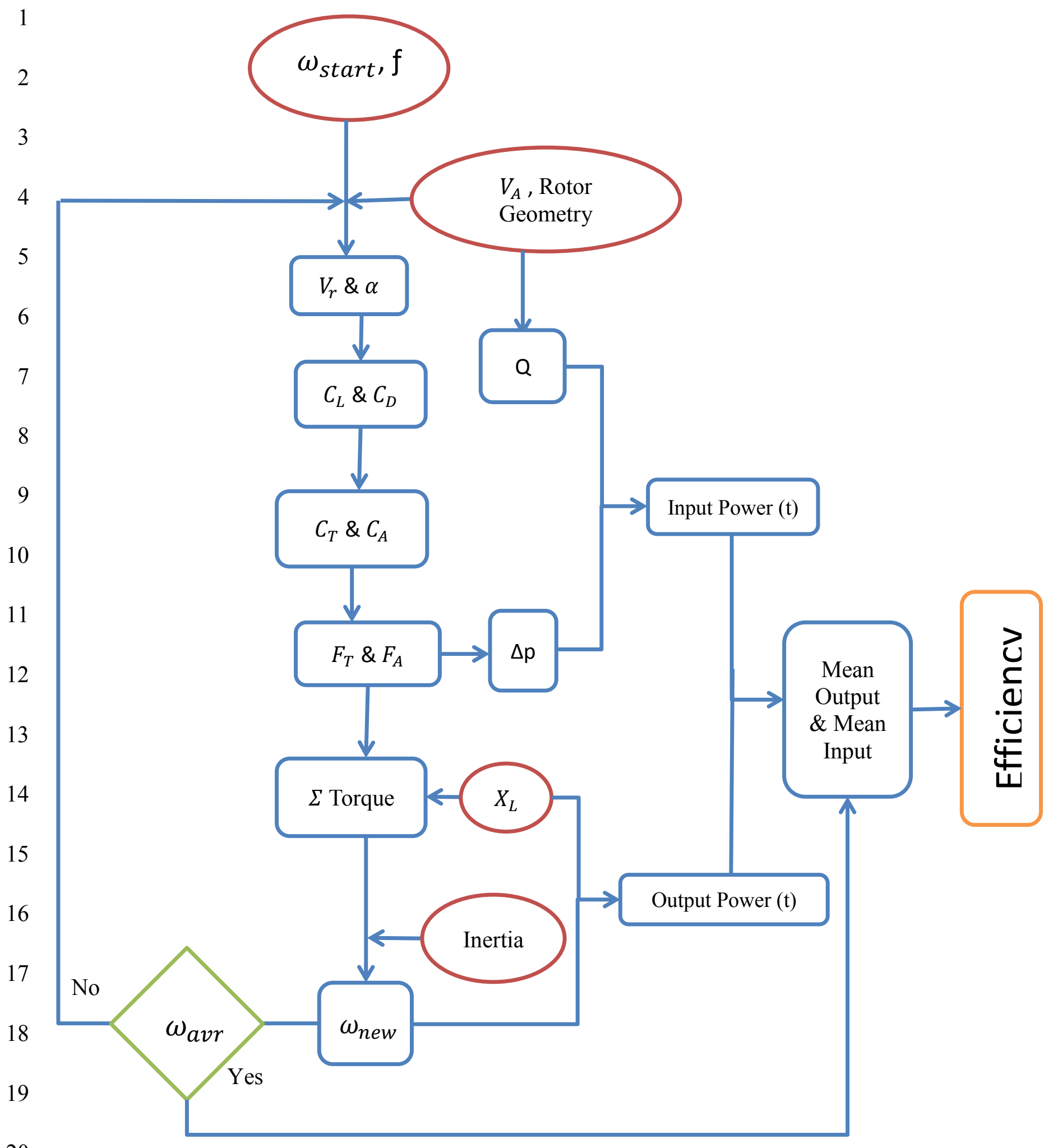




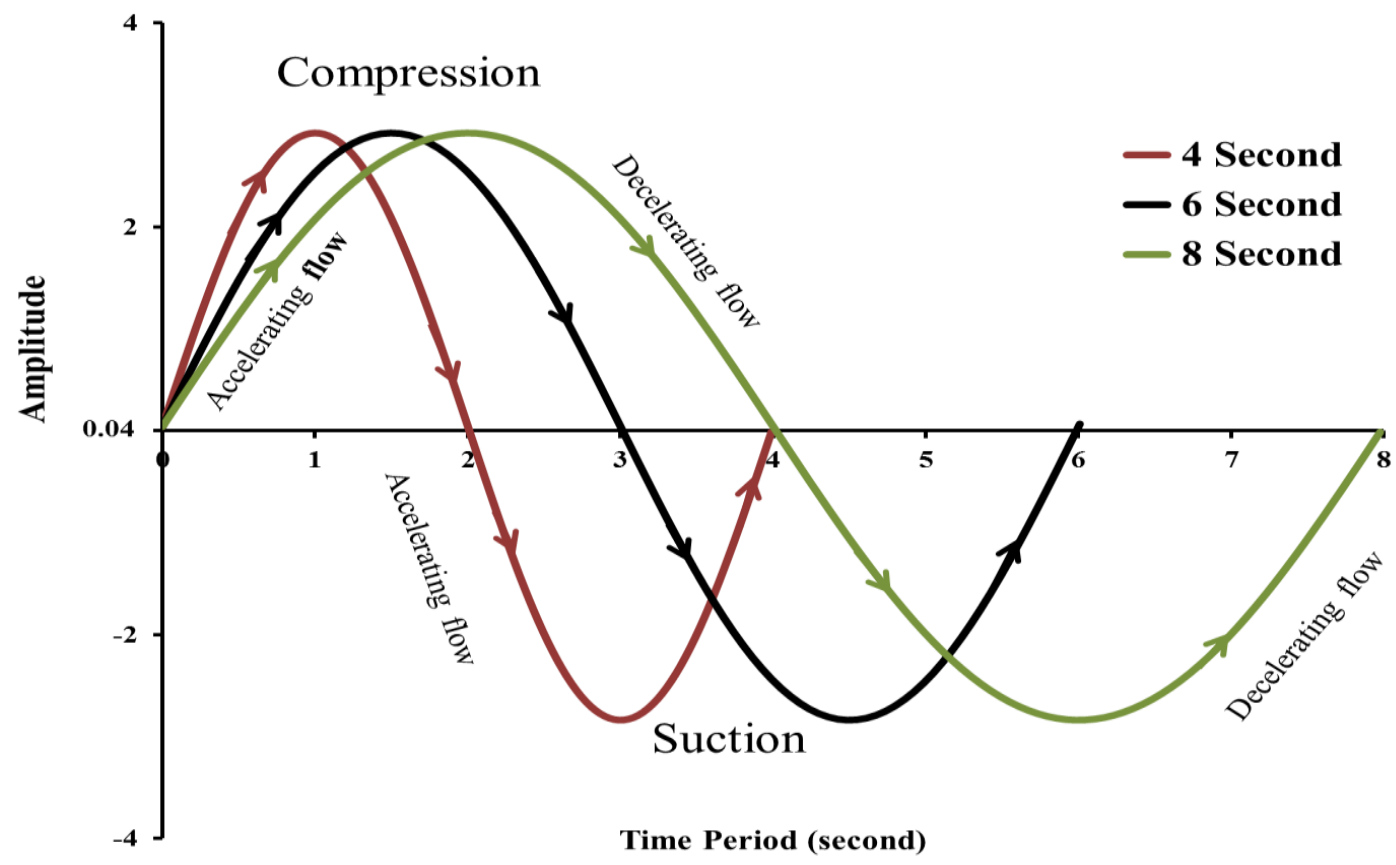

Figure 2 The sinusoidal waves boundary condition, which represents a regular oscillating 3 4

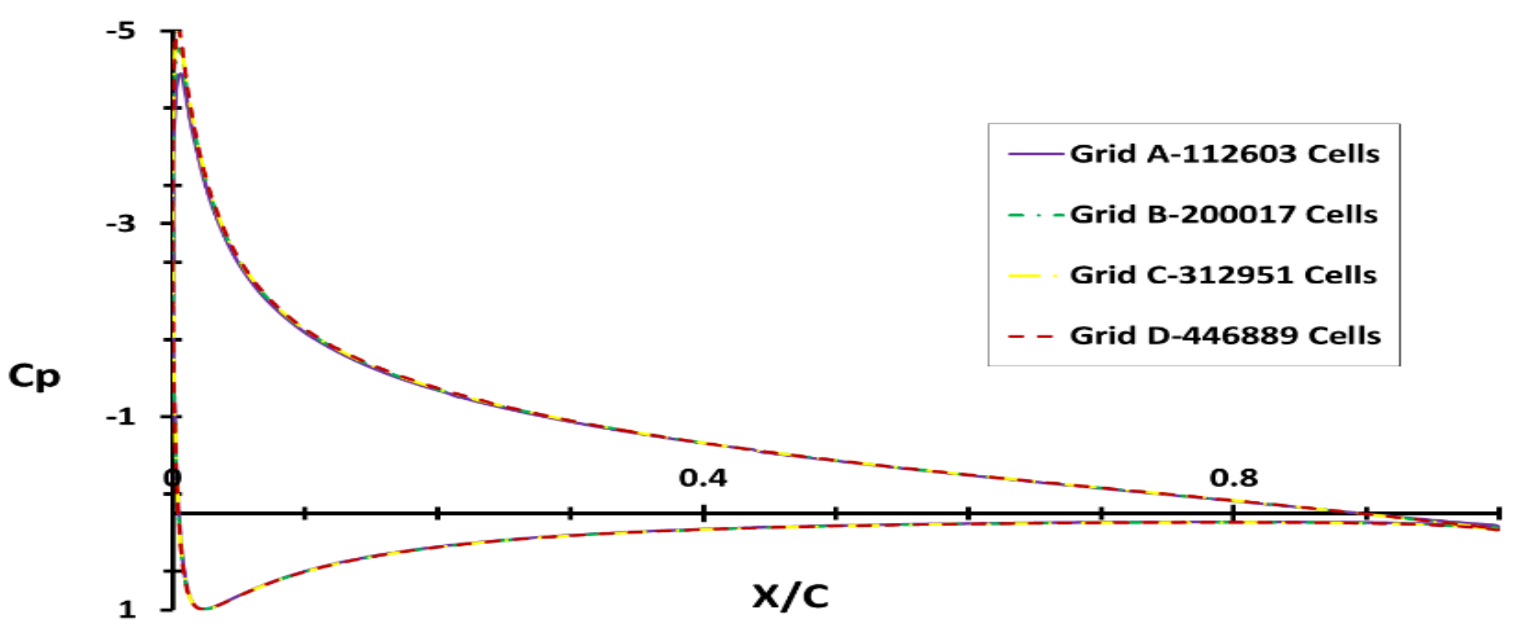

6 Figure 3 Pressure coefficient plotted on the normalized airfoil cord at different grid resolutions 


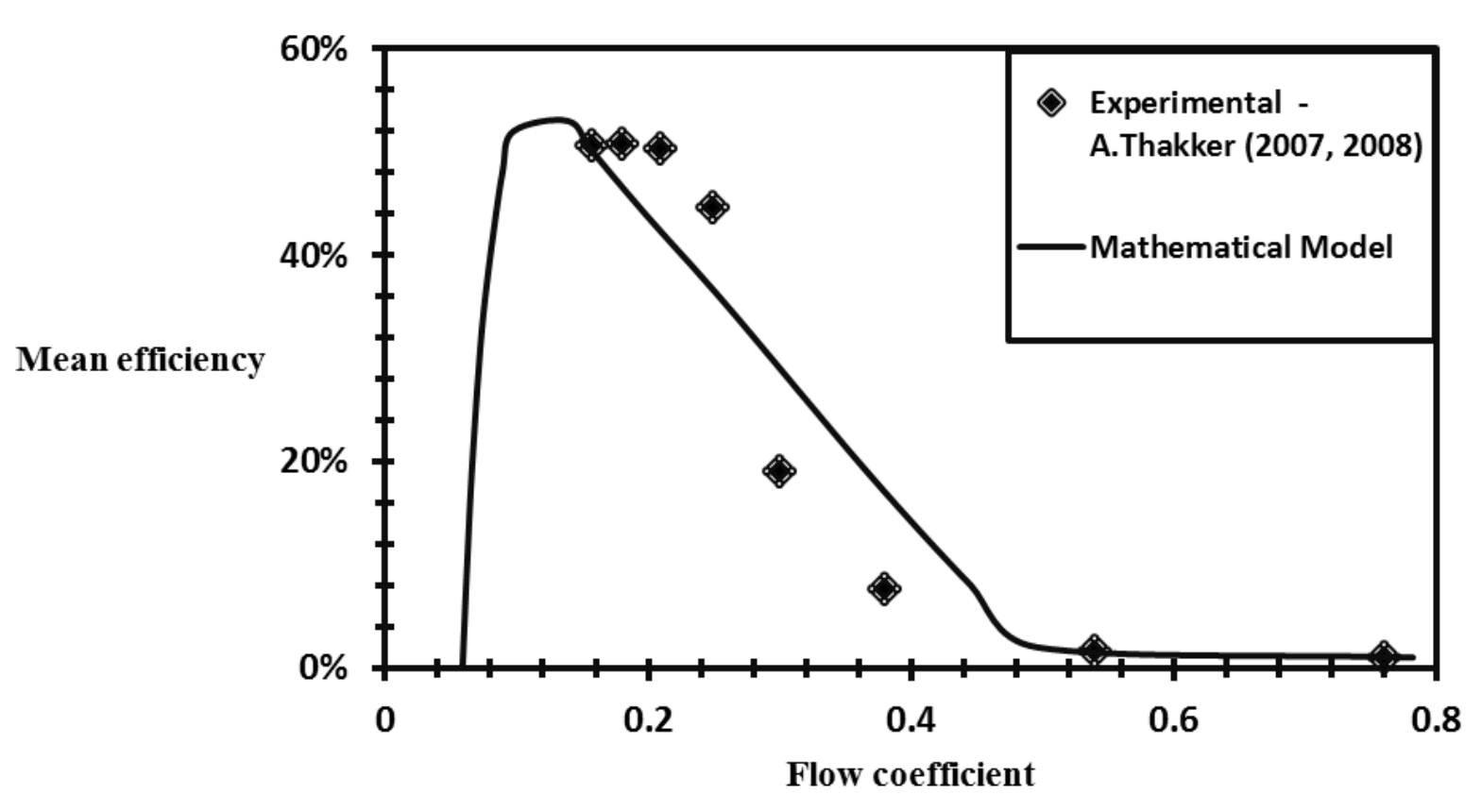

2 Figure 4 Mean efficiency of NACA0015 under sinusoidal flow conditions with solidity $=0.64$

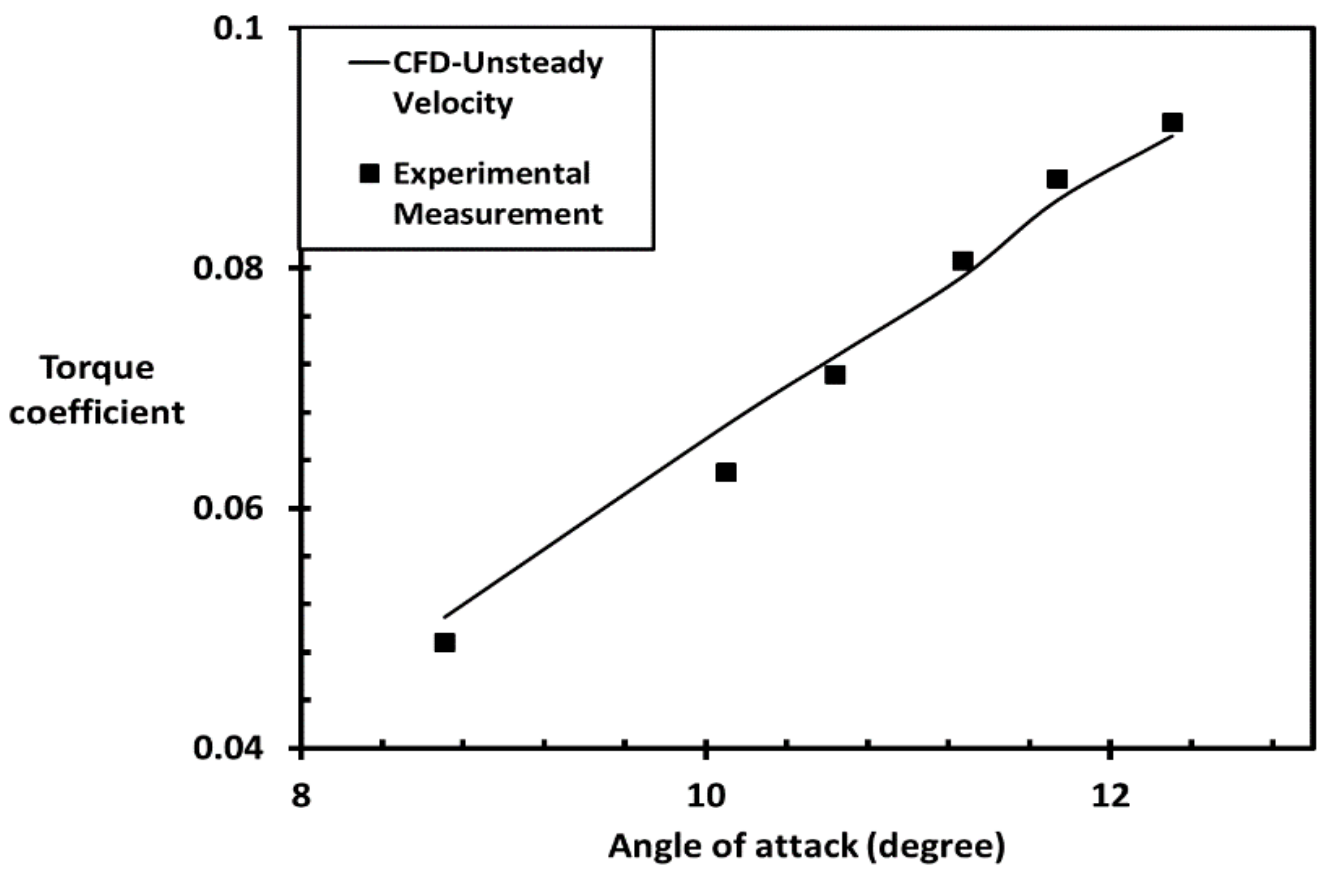

4 Figure 5 Measured torque coefficient from reference (63-65) and calculated torque coefficient from CFD unsteady flow with sinusoidal inlet velocity 

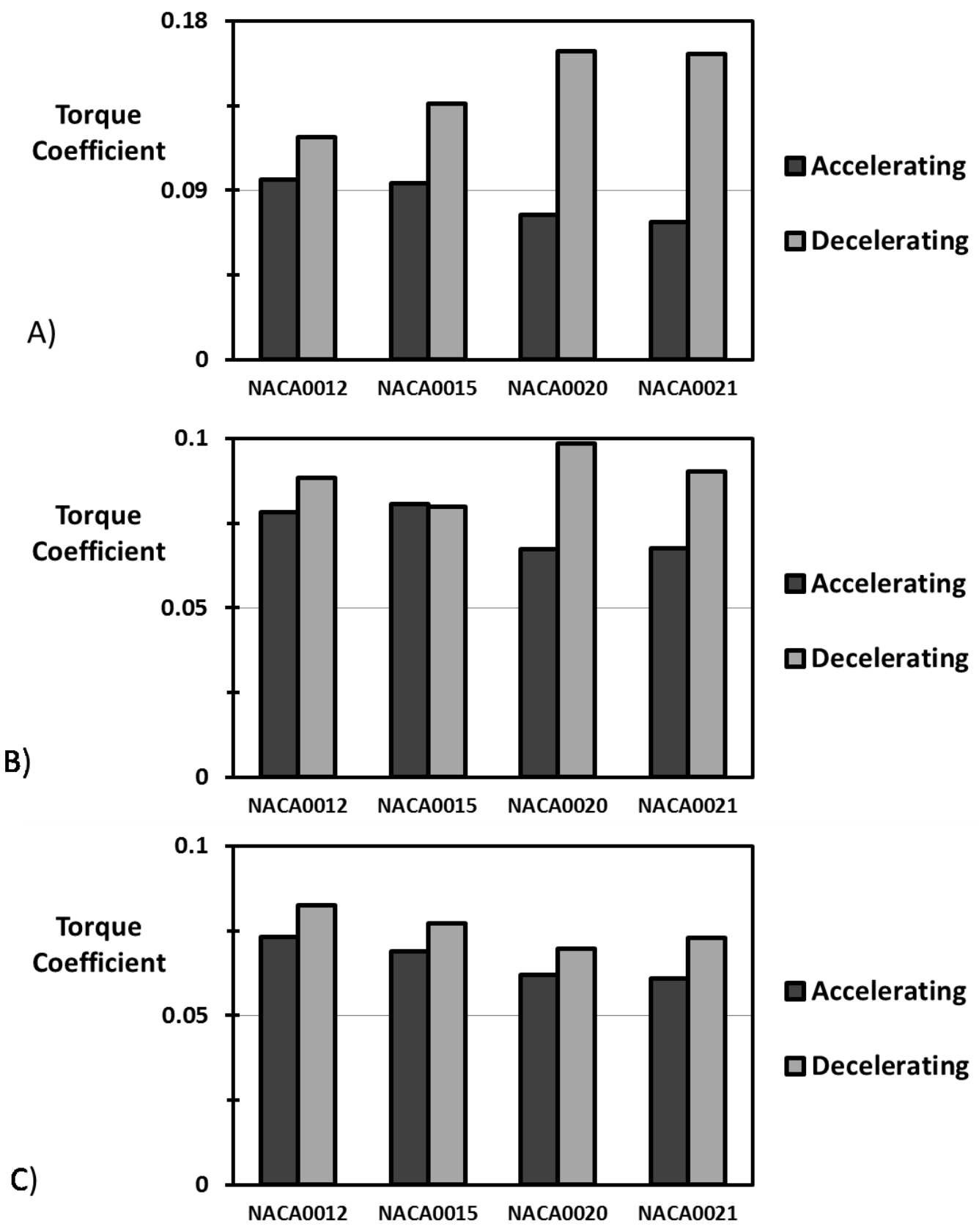

2 Figure 6 Comparisons between the torque coefficient during the accelerating and decelerating flow for four different airfoils, A) $t_{\sin }=4 \mathrm{sec}$, B) $t_{\sin }=6 \mathrm{sec}$ and C) $t_{\sin }=8 \mathrm{sec}$. 


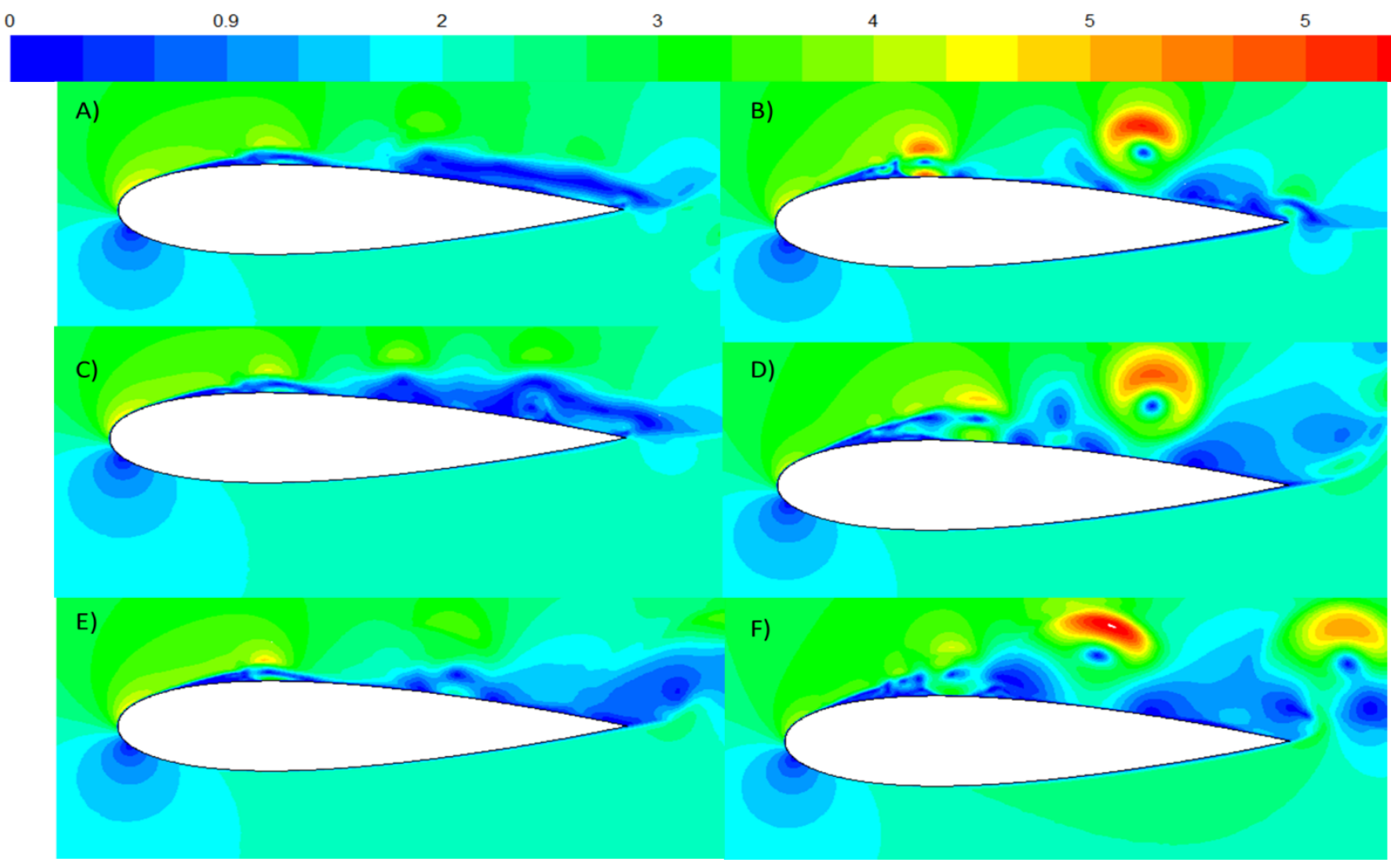

2 Figure 7 Contour of velocity magnitude at velocity equal to $2.08(\mathrm{~m} / \mathrm{s})$ around the NACA0020 3 airfoil for sinusoidal input flow, Accelerating flow A) $t_{\sin }=4 \mathrm{sec}$, C) $t_{\sin }=6 \mathrm{sec}$, E) $t_{\sin }=8 \mathrm{sec}$ and Decelerating flow B) $t_{s i n}=4 \mathrm{sec}$, D) $t_{\sin }=6 \mathrm{sec}$, , F) $t_{s i n}=8 \mathrm{sec}$ 
A)

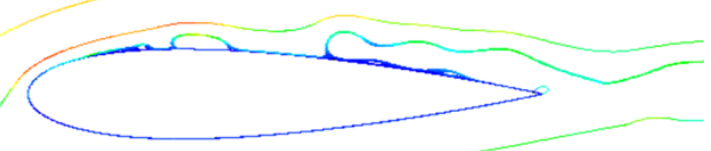

C)

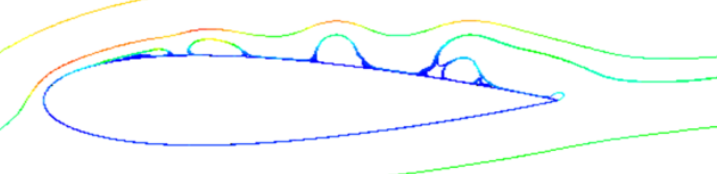

E)

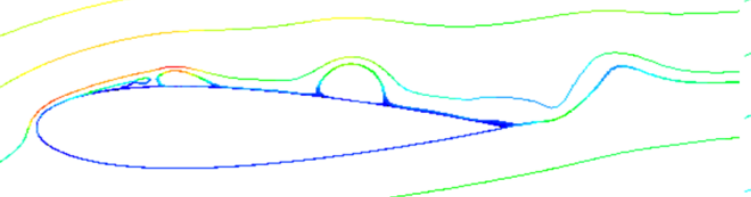

B)

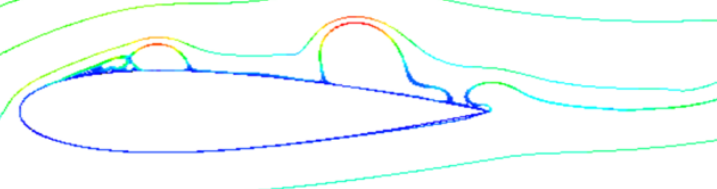

D)

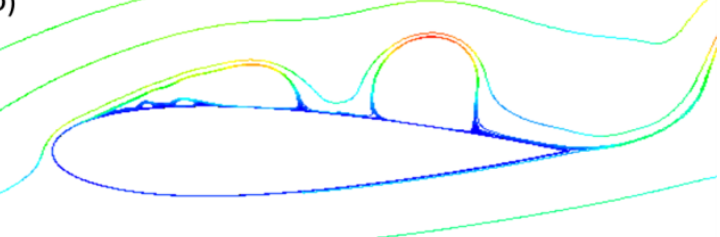

F)

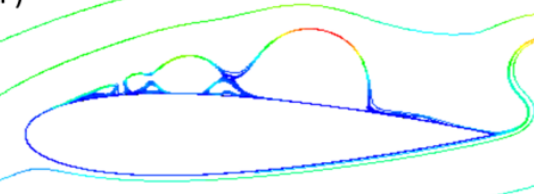

Figure 8 Path line of velocity magnitude at velocity equal to $2.08(\mathrm{~m} / \mathrm{s})$ around the NACA0020 airfoil for sinusoidal input flow, Accelerating flow A) $t_{\sin }=4 \mathrm{sec}$, C) $\left.t_{\sin }=6 \mathrm{sec}, \mathrm{E}\right) t_{\sin }=8 \mathrm{sec}$ and Decelerating flow B) $t_{\sin }=4 \mathrm{sec}$, D) $t_{\sin }=6 \mathrm{sec}$, , F) $t_{\sin }=8 \mathrm{sec}$ 

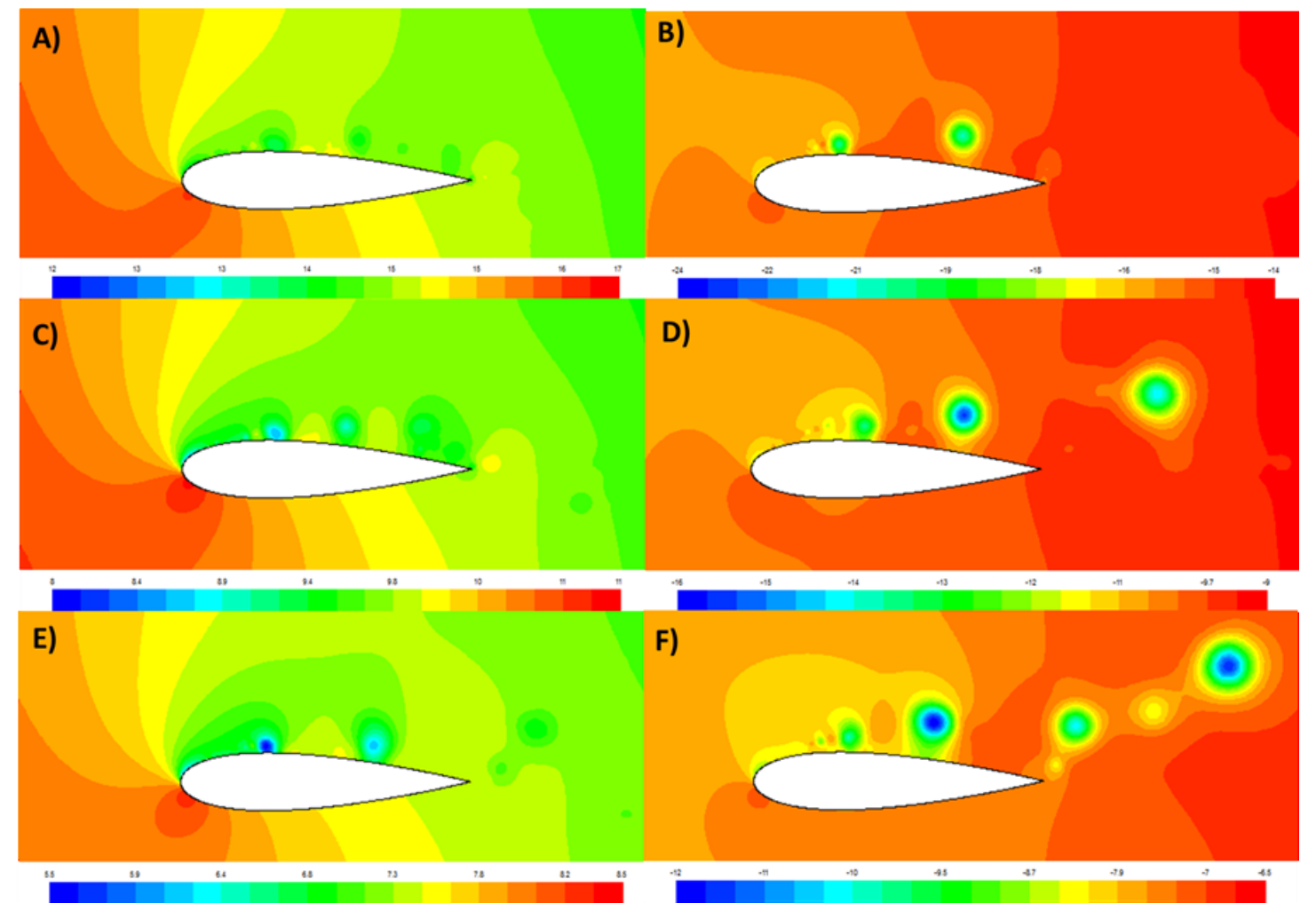

2 Figure 9 Contours of pressure coefficient around the airfoil, Accelerating flow A) $t_{\sin }=4 \mathrm{sec}, \mathrm{C}$ ) $3 t_{s i n}=6 \mathrm{sec}$, E) $t_{s i n}=8 \mathrm{sec}$ and Decelerating flow B) $t_{\sin }=4 \mathrm{sec}$, D) $t_{s i n}=6 \mathrm{sec}$, , F) $t_{s i n}=8 \mathrm{sec}$ 

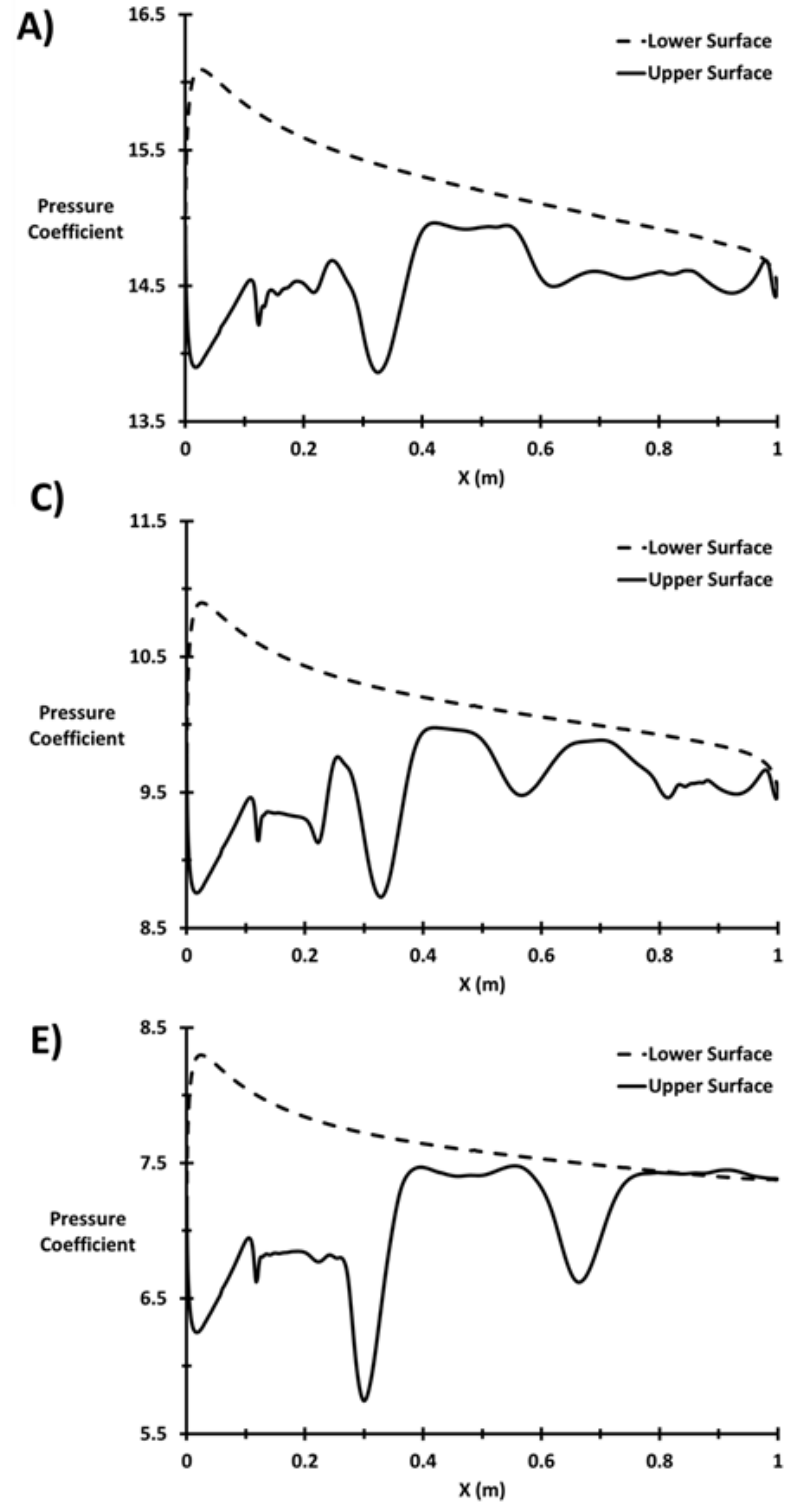

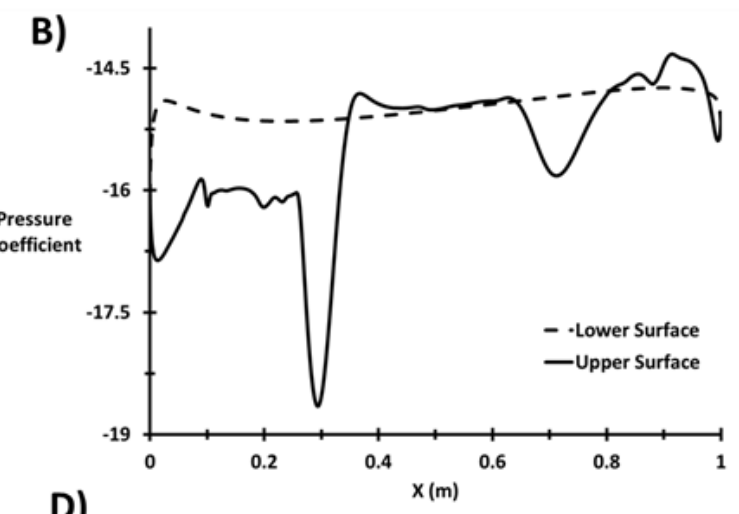

D)
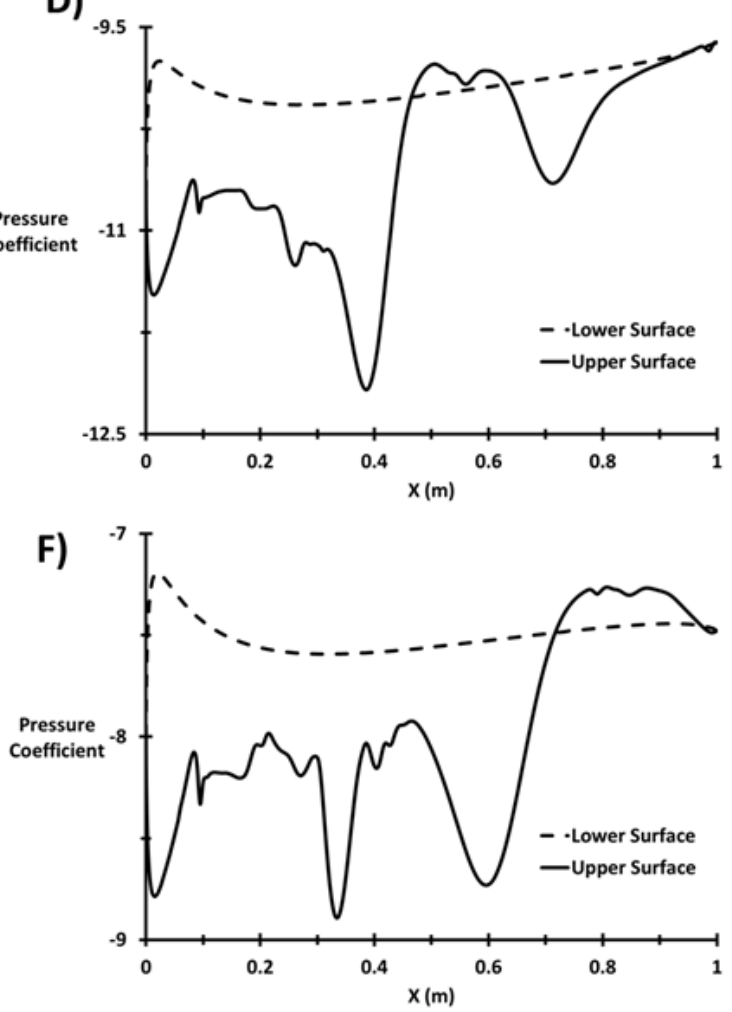

Figure 10 Pressure coefficient distribution on the upper and lower surface of the airfoil, Accelerating flow A) $t_{\sin }=4 \mathrm{sec}, C$ ) $\left.t_{\sin }=6 \mathrm{sec}, E\right) t_{\sin }=8 \mathrm{sec}$ and Decelerating flow B) $t_{\sin }=4$ $\sec , D) t_{\text {sin }}=6 \mathrm{sec}$, , F) $t_{\text {sin }}=8 \mathrm{sec}$ 

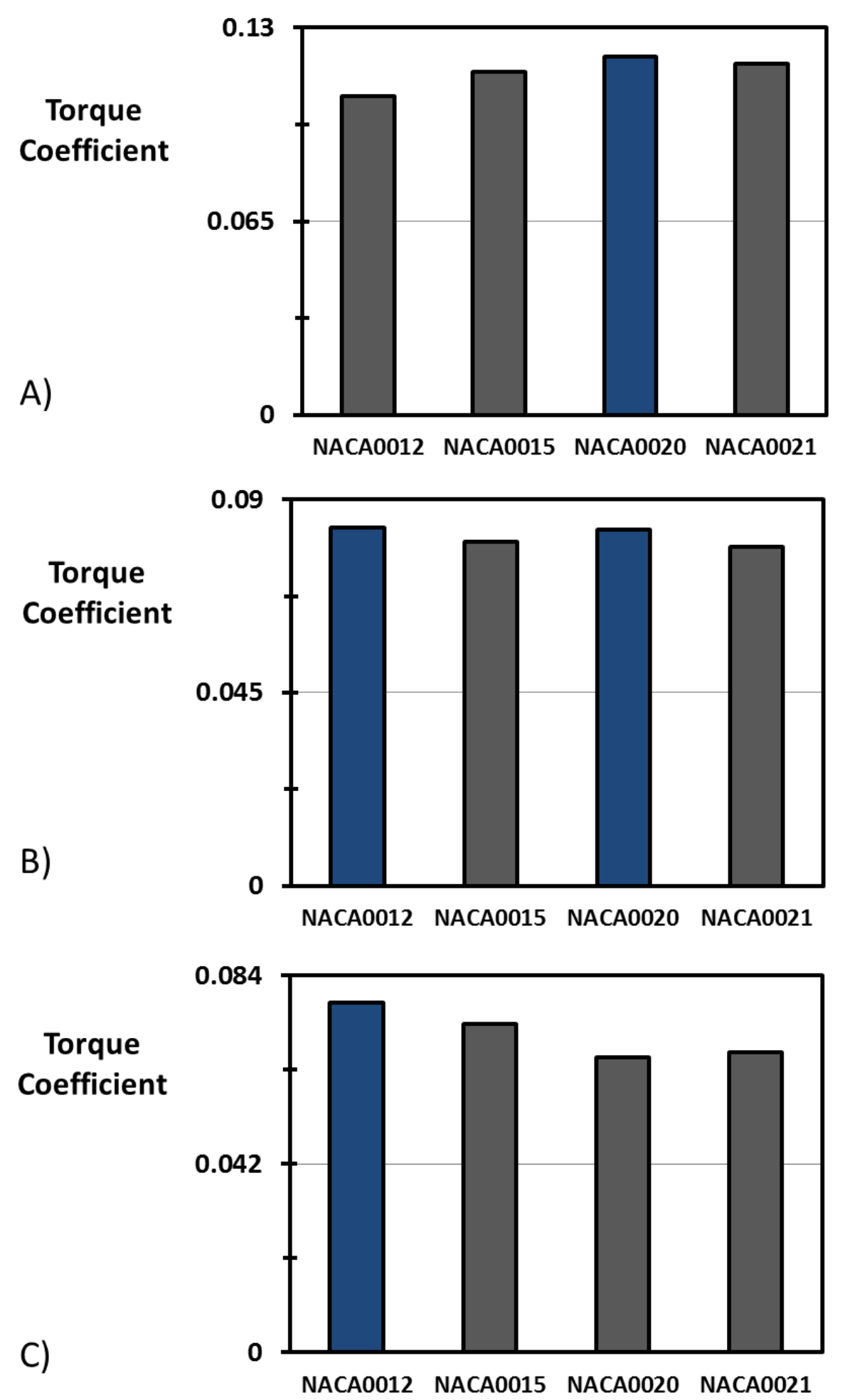

2 Figure 11 Total average values for the torque coefficient during the velocity cycle for the four different airfoils, A) $\left.t_{\sin }=4 \mathrm{sec}, \mathrm{B}\right) t_{\sin }=6 \mathrm{sec}$ and D) $t_{\sin }=8 \mathrm{sec}$. 

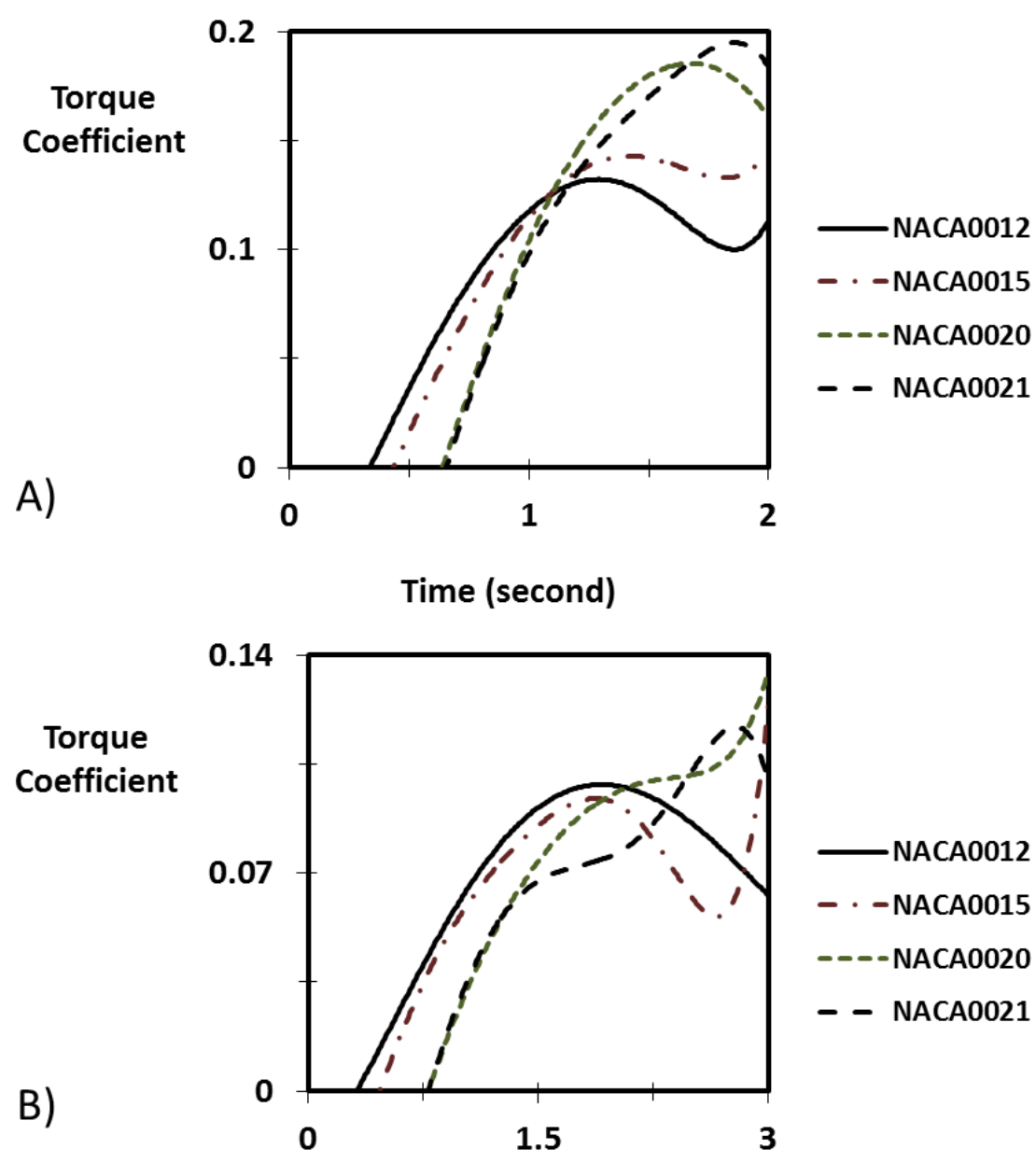

Time (second)

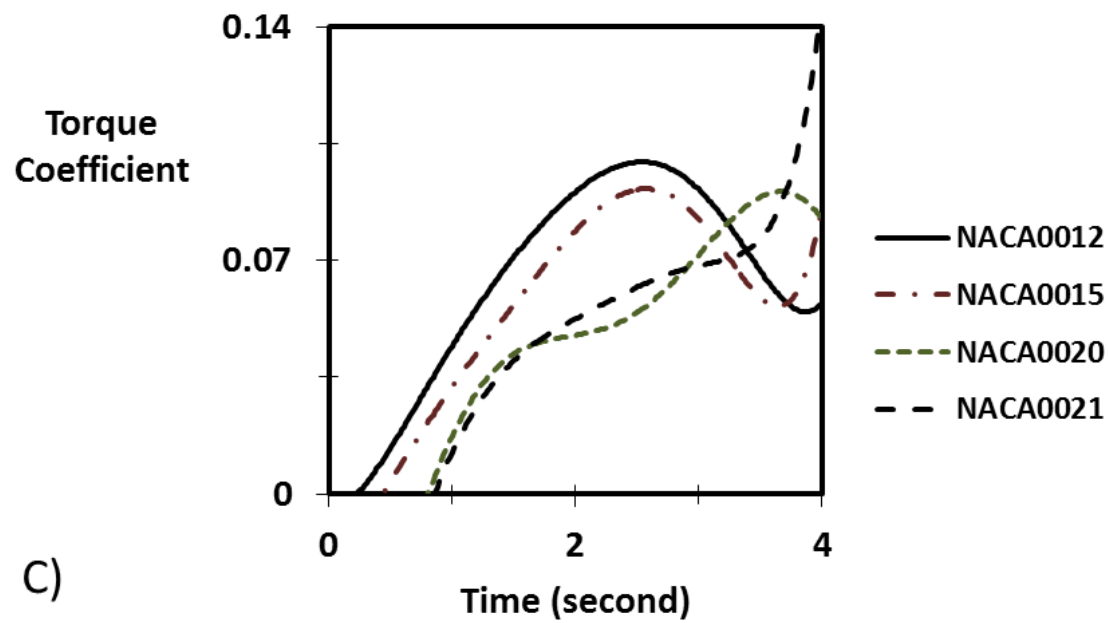

Figure 12 The instantaneous values for the torque coefficient during the compression cycle for four different airfoils, A) $t_{\sin }=4 \mathrm{sec}$, B) $t_{\sin }=6 \mathrm{sec}$ and D) $t_{\sin }=8 \mathrm{sec}$. 


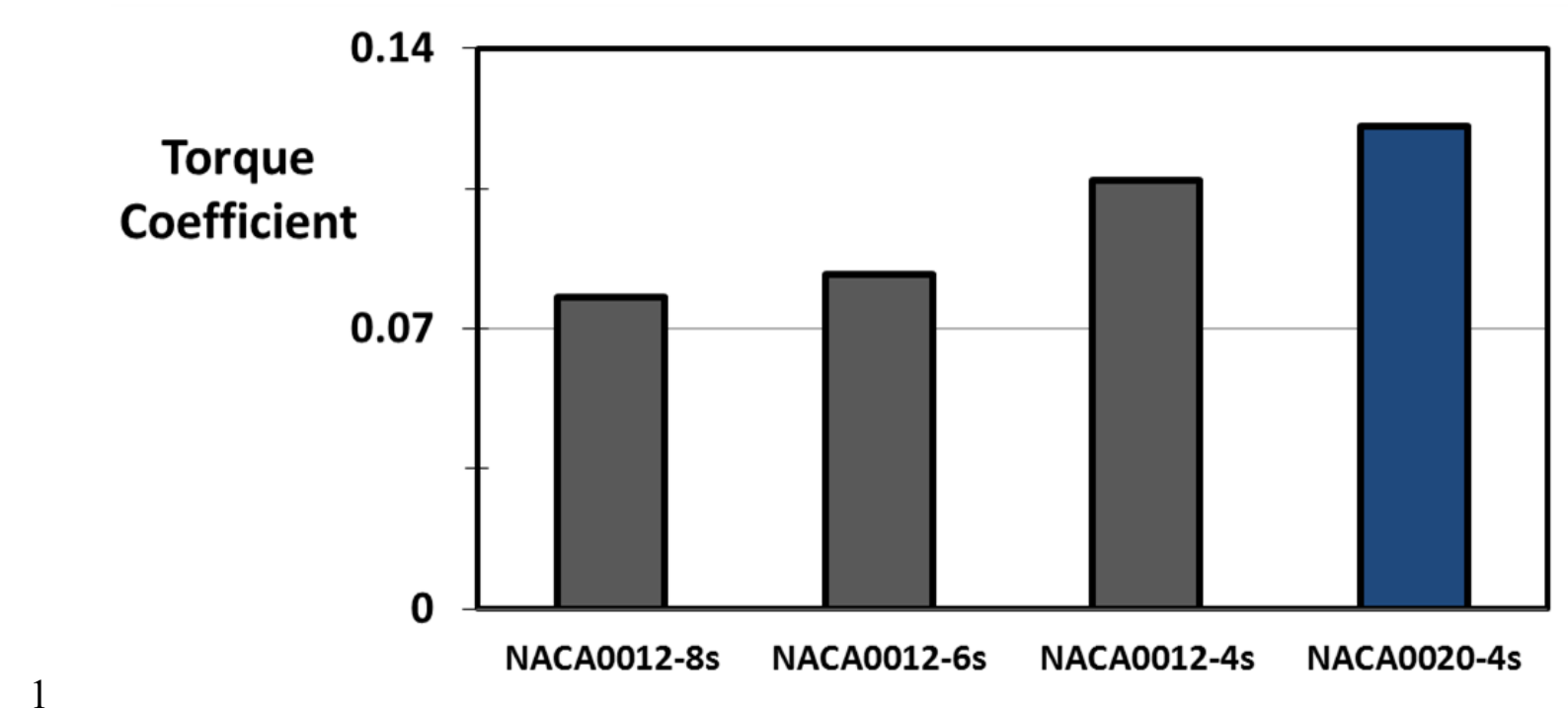

2 Figure 13 The comparison between the maximum torque coefficients for each velocity cycle.

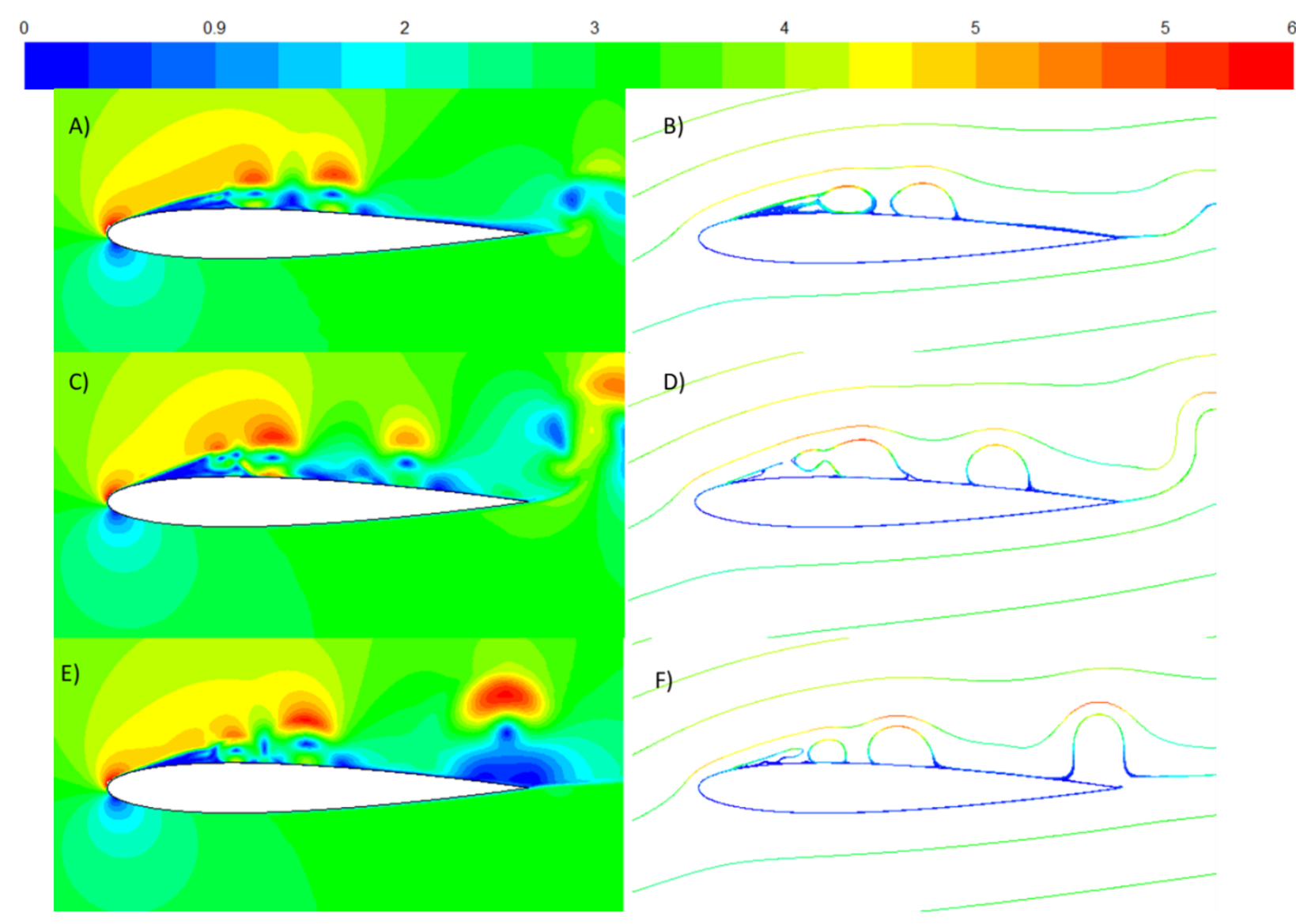

$4 \quad$ Figure 14 Contours of velocity magnitude at maximum velocity equal to 2.92 $(\mathrm{m} / \mathrm{s})$ around the NACA0012 airfoil for sinusoidal input flow, A) $\left.t_{\sin }=4 \mathrm{sec}, \mathrm{C}\right)$ $\left.t_{\sin }=6 \mathrm{sec}, \mathbf{E}\right) t_{\sin }=8 \mathrm{sec}$, and path line colored by velocity magnitude for B) $t_{\sin }=4 \mathrm{sec}$, D) $t_{\sin }=6 \mathrm{sec}$, F) $t_{\sin }=8 \mathrm{sec}$ 

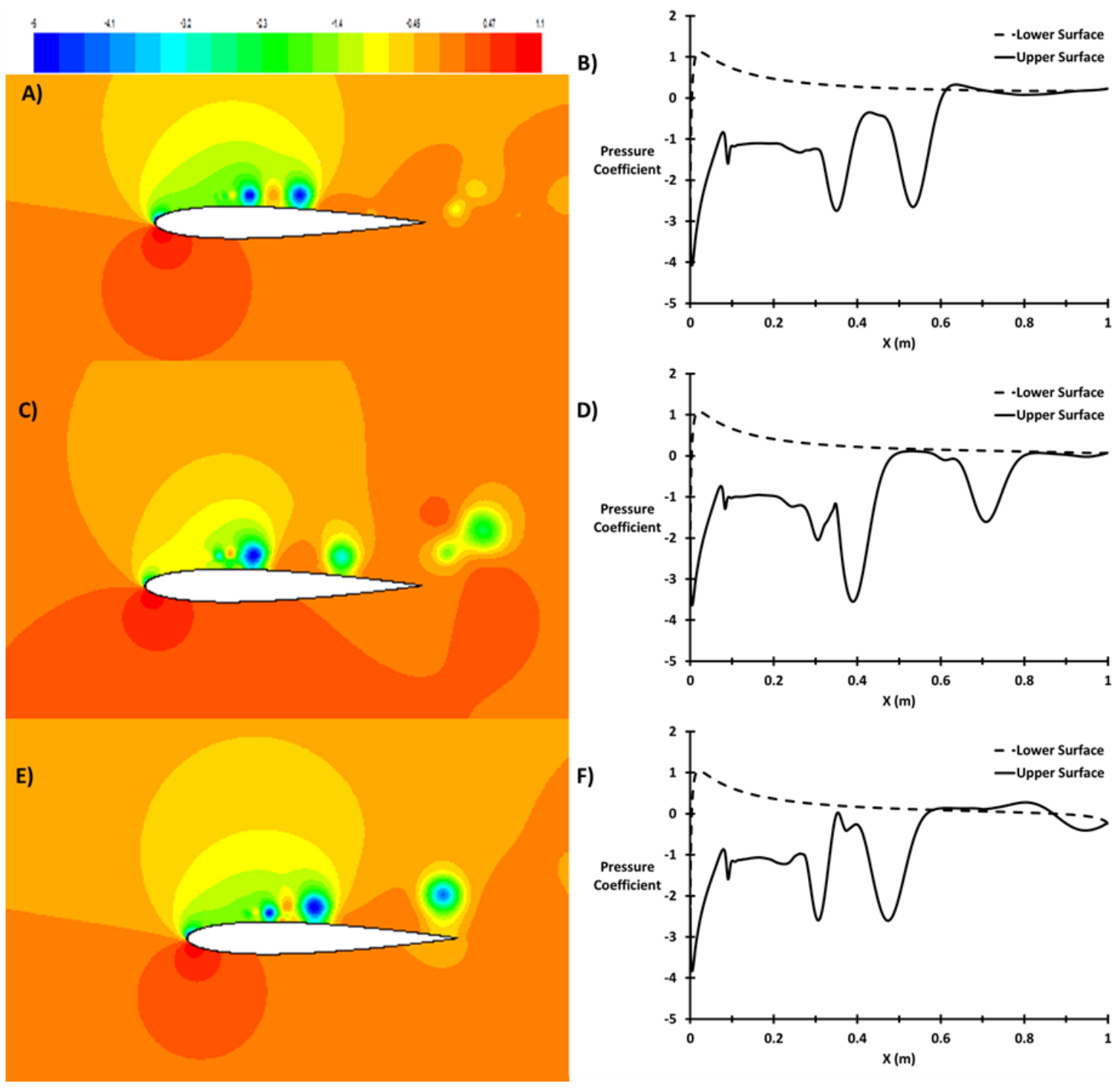

Figure 15 Contours of pressure coefficient A) $t_{\sin }=4 \mathrm{sec}$, C) $\left.t_{\sin }=6 \mathrm{sec}, \mathbf{E}\right) t_{\sin }=8 \mathrm{sec}$, and Pressure coefficient distribution on the upper and lower surface of the airfoil B) $t_{\sin }=\mathbf{4} \mathrm{sec}$, D) $\left.t_{\sin }=6 \mathrm{sec}, \mathbf{F}\right) t_{\sin }=8 \mathrm{sec}$ 


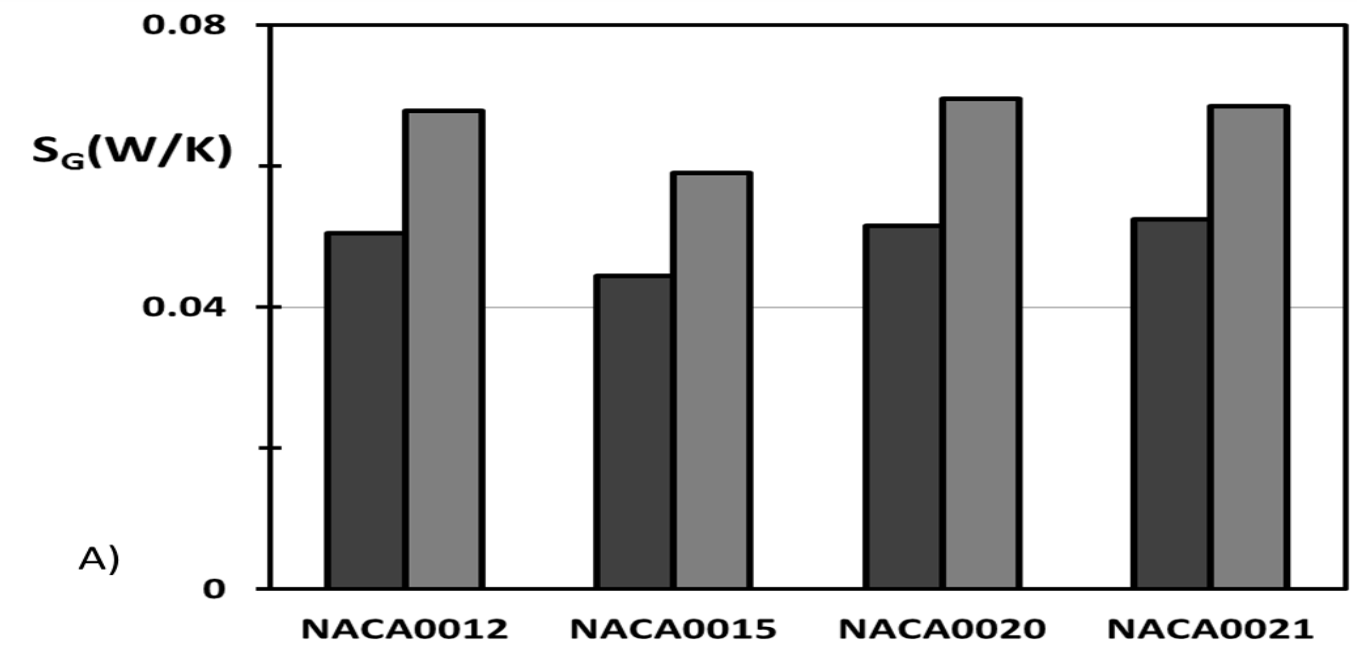

DAccelerating

$\square$ Decelerating

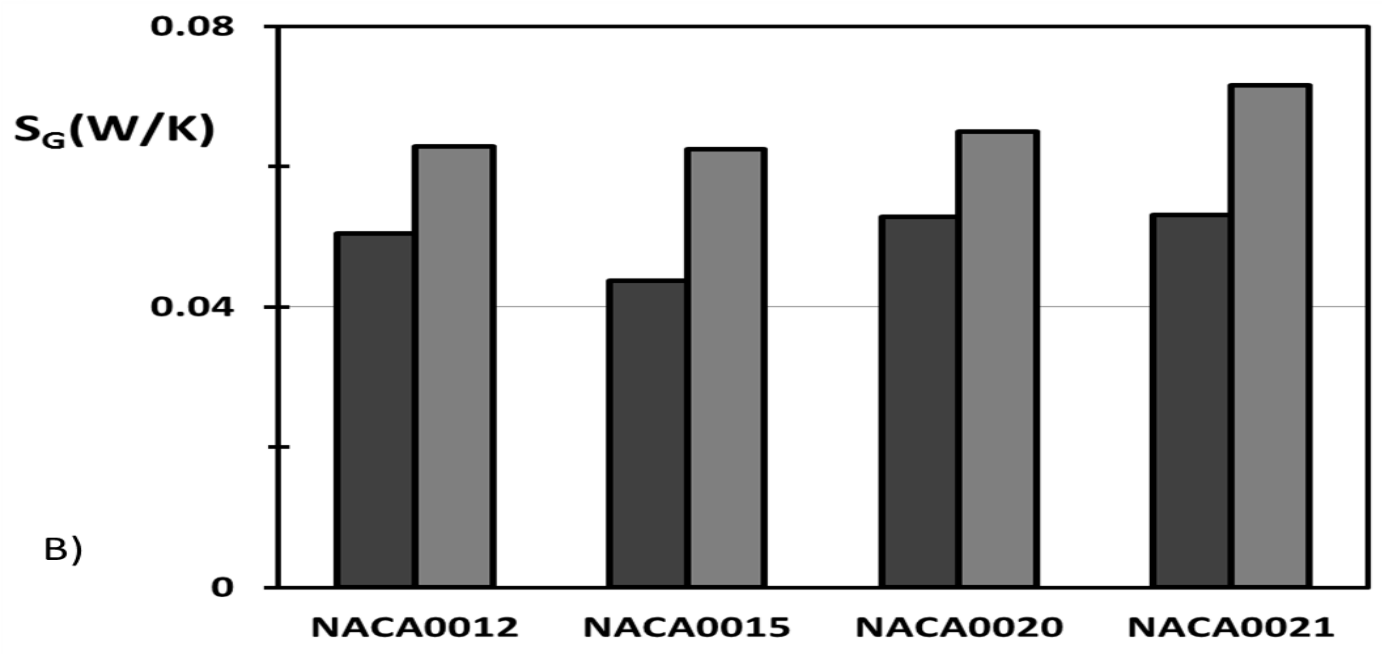

Accelerating $\square$ Decelerating

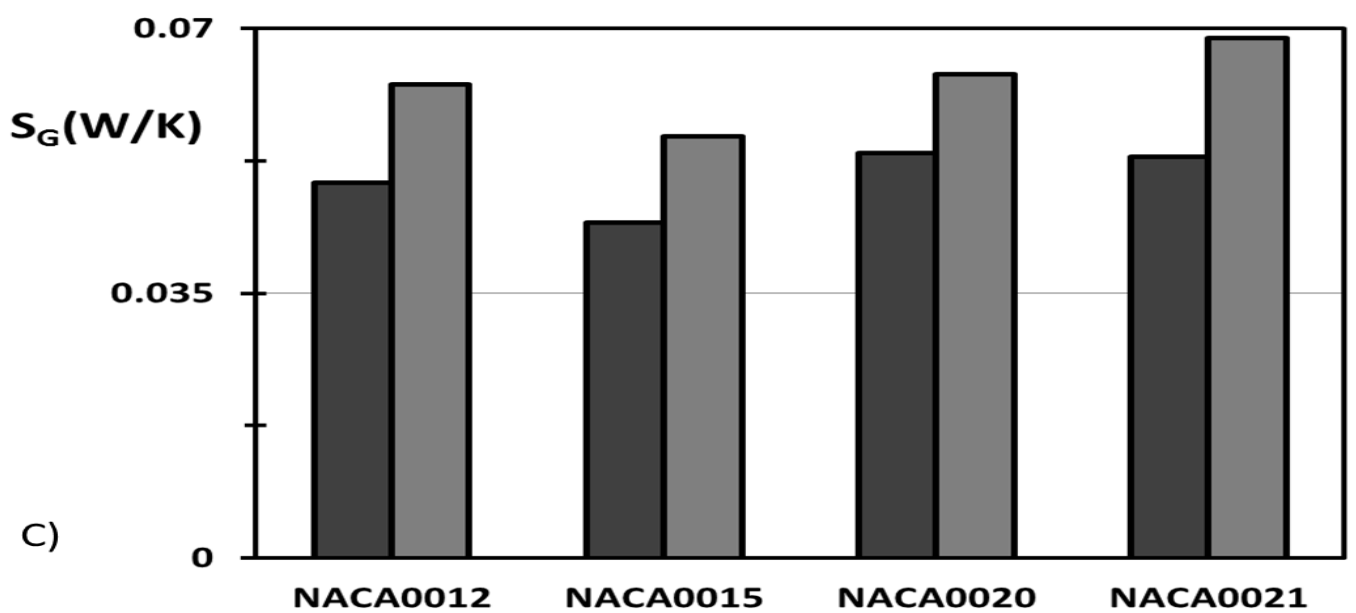

$\square$ Accelerating
$\square$ Decelerating

Figure 16 Comparisons between the global entropy generation rate during the accelerating and decelerating flow for the four different airfoils, A) $\left.t_{\sin }=4 \mathrm{sec}, \mathrm{B}\right) t_{\sin }=6 \mathrm{sec}$ and $\left.\mathrm{C}\right) t_{\sin }=8 \mathrm{sec}$. 
A)

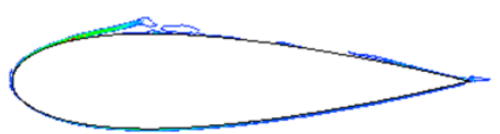

C)

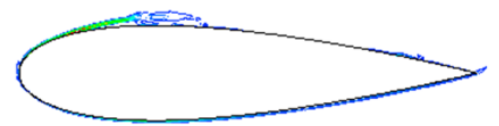

E)

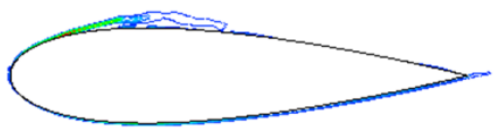

B)

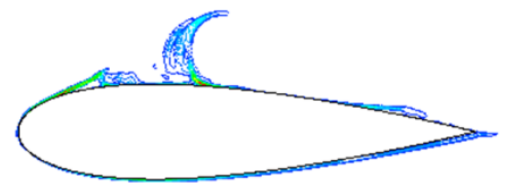

D)

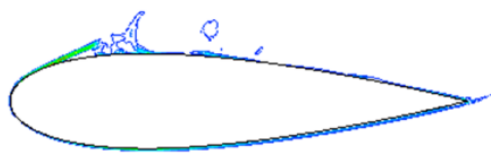

F)

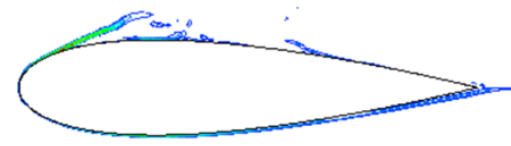

Figure 17 Contour of global entropy generation rate at velocity equal to $2.08(\mathrm{~m} / \mathrm{s})$ around the NACA0021 airfoil for sinusoidal input flow, A) accelerating flow with $t_{\sin }=4 \mathrm{sec}$, B) decelerating flow with $t_{\sin }=4 \mathrm{sec}, \mathrm{C}$ ) accelerating flow with $t_{\sin }=6 \mathrm{sec}$, D) decelerating flow with $t_{\sin }=6 \mathrm{sec}$, E) accelerating flow with $t_{\sin }=8 \mathrm{sec}$, F) decelerating flow with $t_{\sin }=8 \mathrm{sec}$. 

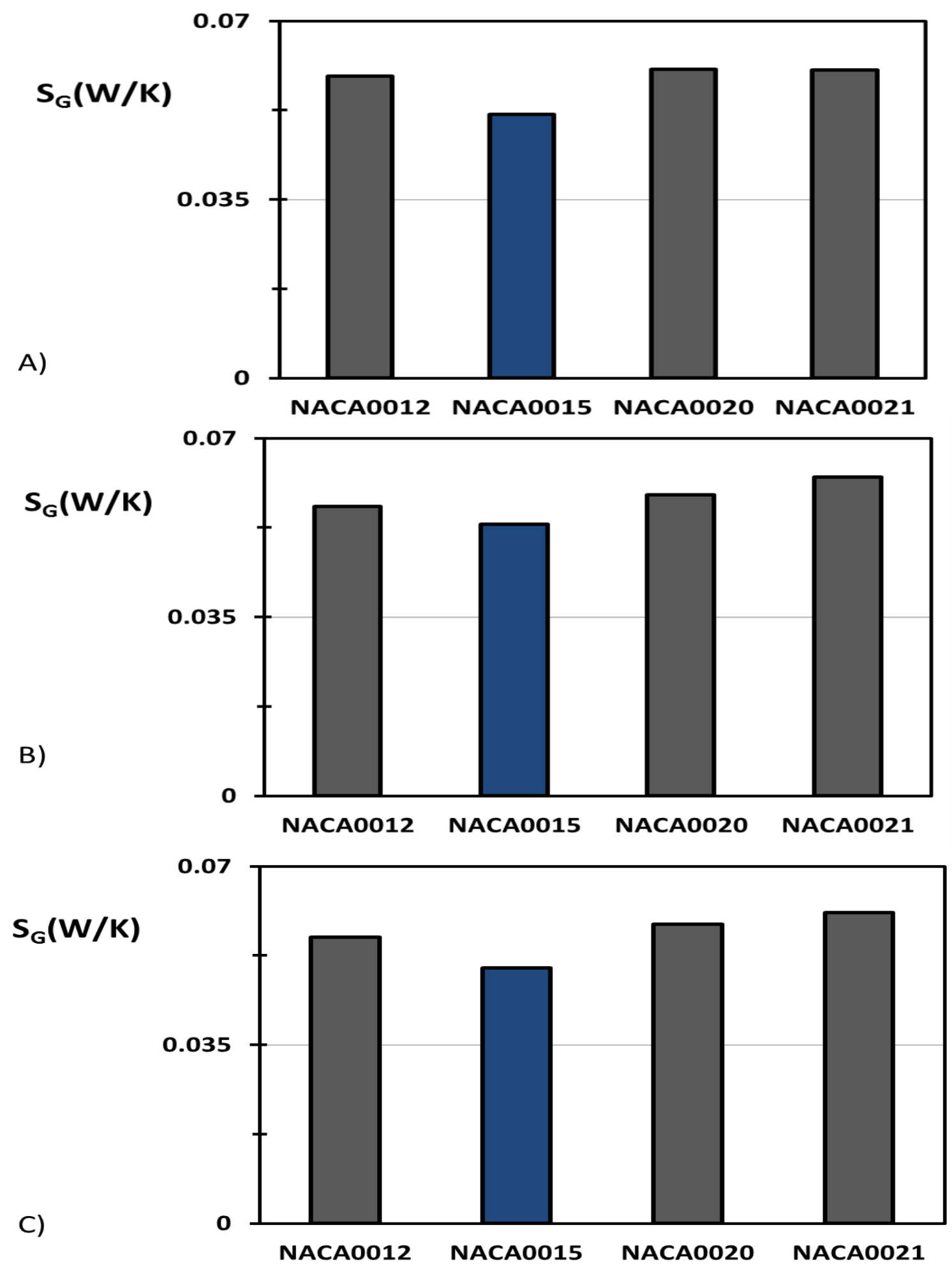

Figure 18 Total average values for the global entropy generation rate during the velocity cycle for four different airfoils, A) $t_{\sin }=4 \mathrm{sec}$, B) $t_{\sin }=6 \mathrm{sec}$ and D) $t_{\sin }=8 \mathrm{sec}$. 


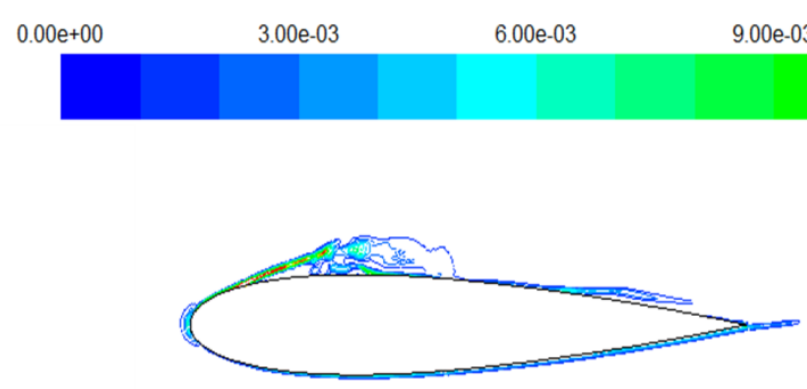

A)

c)

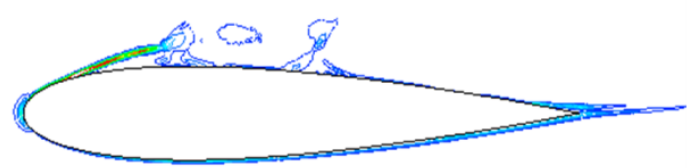

B)

Figure 19 Contour of global entropy generation rate at maximum velocity equal to $2.92(\mathrm{~m} / \mathrm{s})$ around the NACA0015 airfoil for sinusoidal input flow, A) $t_{\sin }=4 \mathrm{sec}, \mathrm{B} t_{\sin }=6 \mathrm{sec}$ and D) $t_{\sin }=8$ sec.

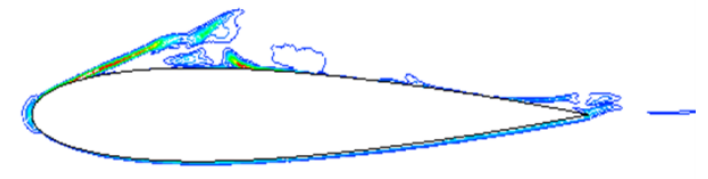



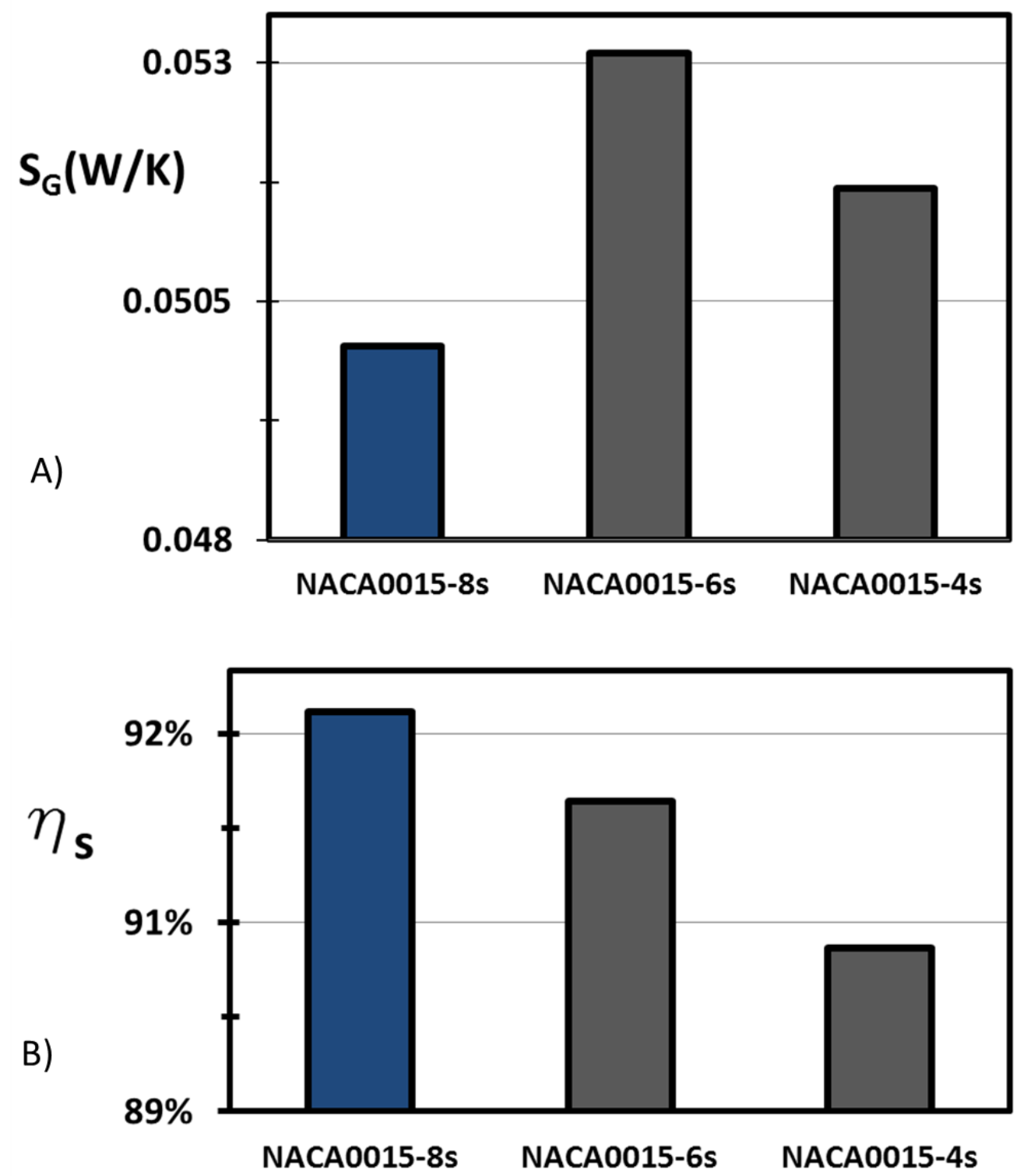

2 Figure 20 The comparison between the NACA0015 at three different time periods $(8 \mathrm{sec}, 6 \mathrm{sec}$ and $4 \mathrm{sec}), \mathrm{A})$ the global entropy generation rate and $B$ ) the second law efficiency. 


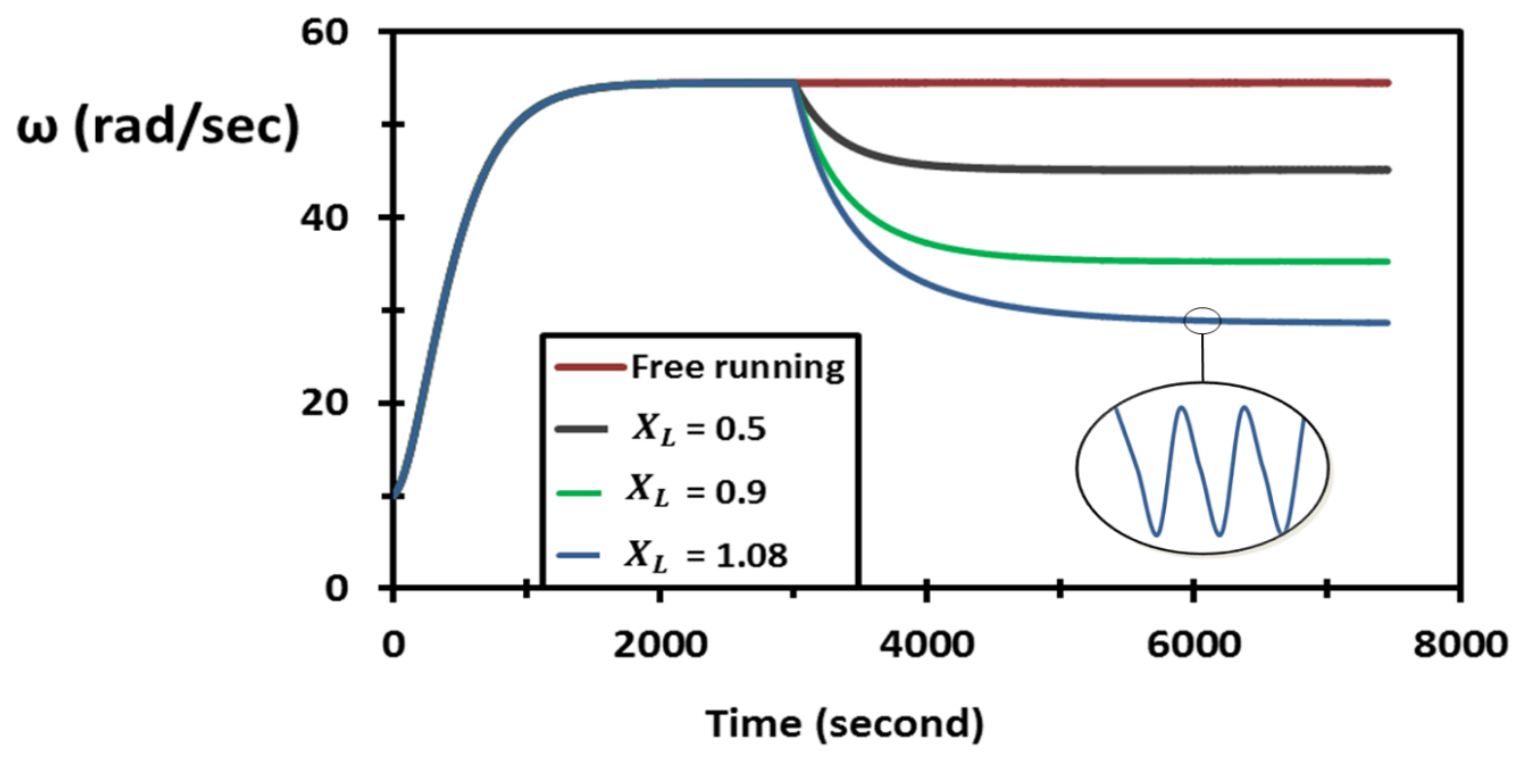

2 Figure 21 Angular velocity variations with time for different loading torque coefficient. 

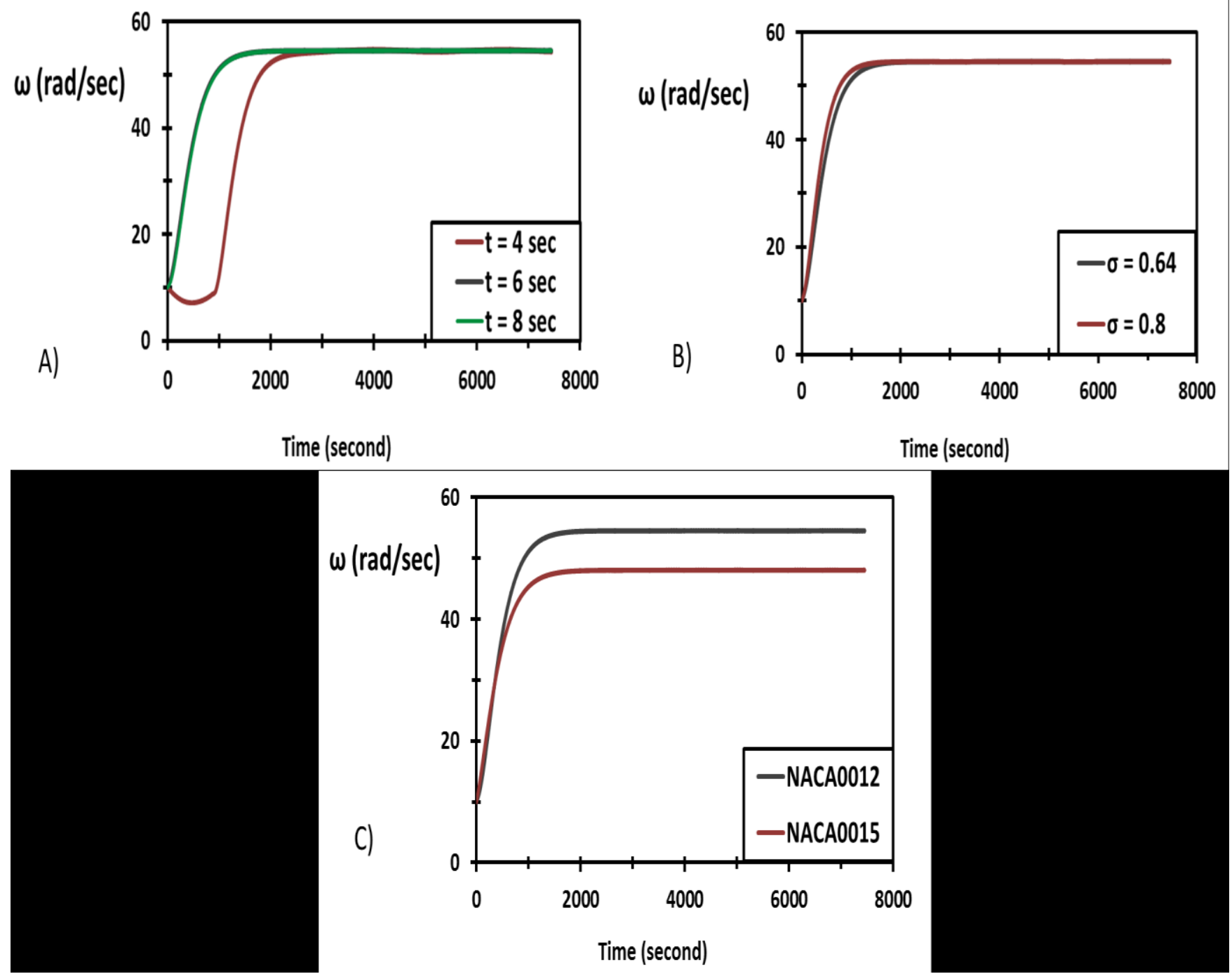

Figure 22 Angular velocity variation with time in free running condition, A) different time period $\left(t_{\sin }=4 \mathrm{sec}, 6 \mathrm{sec}\right.$ and $\left.\left.8 \mathrm{sec}\right), \mathrm{B}\right)$ different solidity $(0.64$ and 0.8$)$ and $\left.C\right)$ different airfoils section (NACA0012 and NACA0015). 

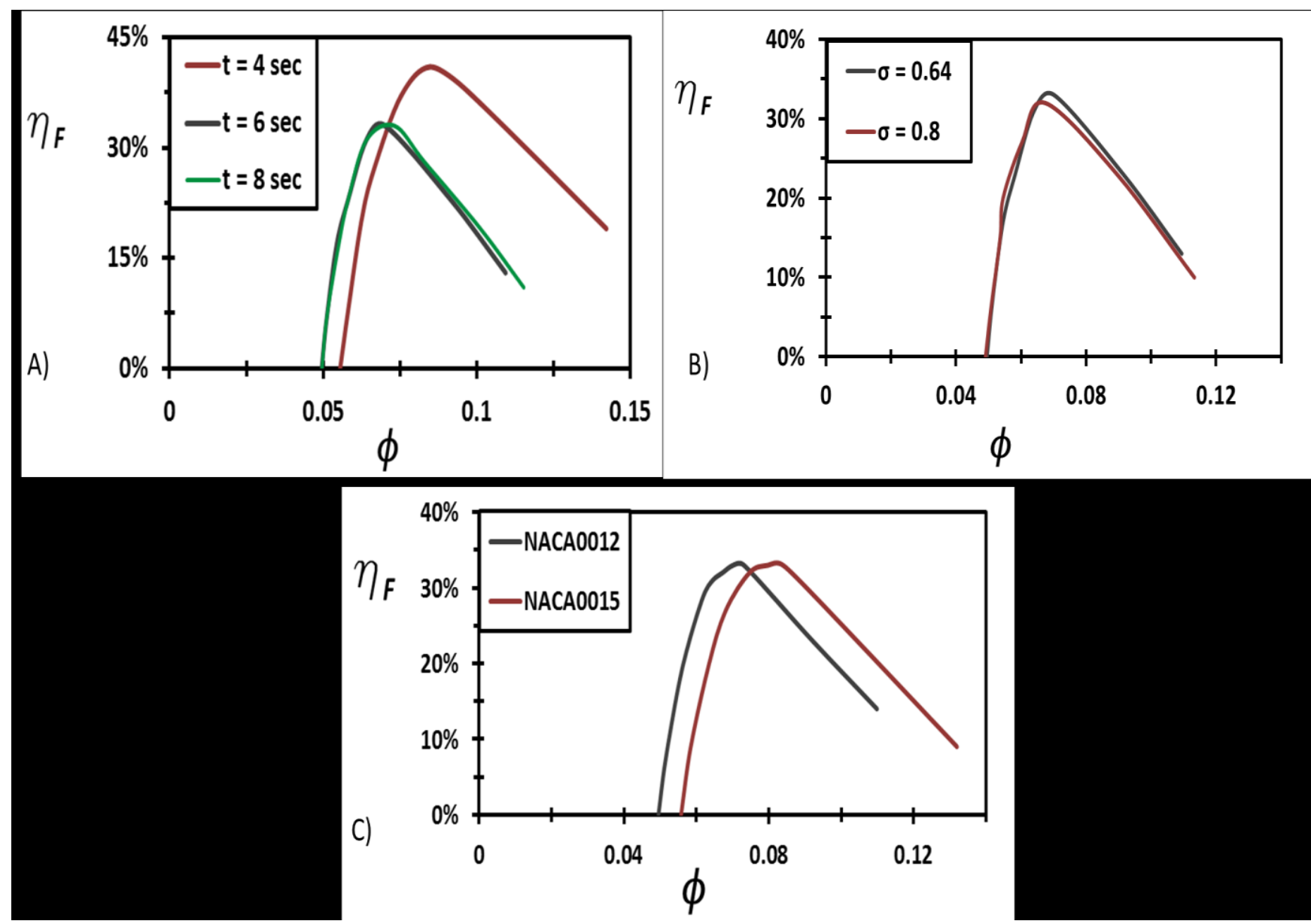

2 Figure 23 The mean efficiency of turbine under sinusoidal flow conditions, A) different time 3 periods $\left(t_{\sin }=4 \mathrm{sec}, 6 \mathrm{sec}\right.$ and $\left.\left.8 \mathrm{sec}\right), \mathrm{B}\right)$ different solidity $(0.64$ and 0.8$)$ and $\left.C\right)$ different airfoils section (NACA0012 and NACA0015). 


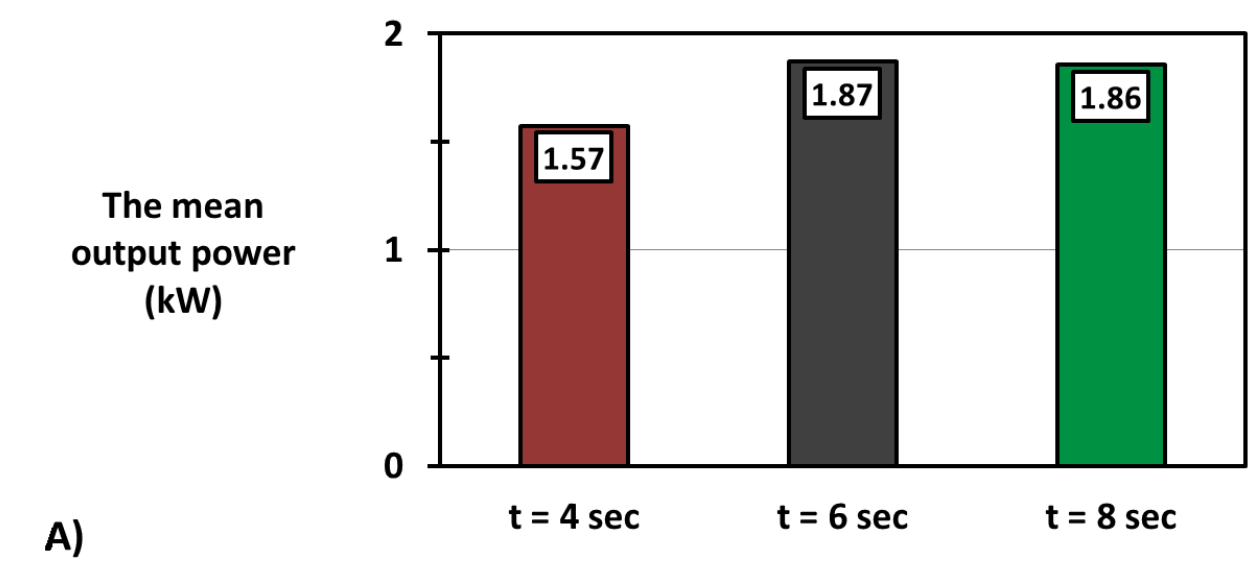

B)
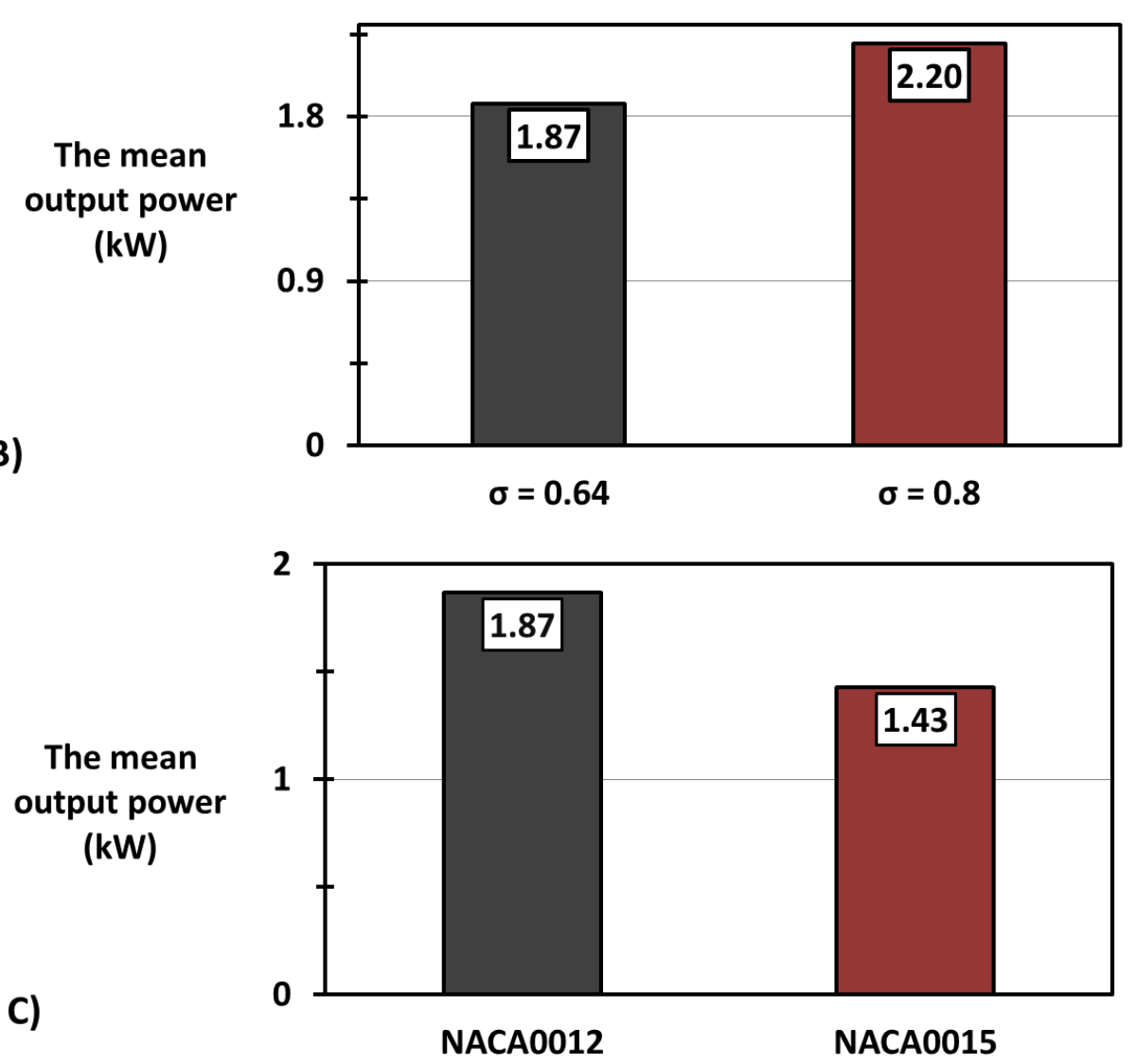

Figure 24 The value of output power for the turbine under sinusoidal flow conditions, $A$ ) different time periods $\left(t_{\sin }=4 \mathrm{sec}, 6 \mathrm{sec}\right.$ and $\left.8 \mathrm{sec}\right)$, B) different solidity (0.64 and 0.8$)$ and C) different airfoils section (NACA0012 and NACA0015). 
Table 1 Specification of grids

\begin{tabular}{|c|c|c|c|c|c|}
\hline Grid & No. of Cells & First cell & Growth rate & Aspect ratio & Equi-Angle skew \\
\hline \hline A & 112603 & $1 \times 10^{-4}$ & 1.02 & 1.996 & 0.429 \\
\hline B & 200017 & $1 \times 10^{-5}$ & 1.015 & 2.466 & 0.475 \\
\hline C & 312951 & $1 \times 10^{-5}$ & 1.012 & 2.376 & 0.514 \\
\hline D & 446889 & $1 \times 10^{-6}$ & 1.01 & 2.551 & 0.513 \\
\hline
\end{tabular}

3 4 Table 2 The percentage of torque coefficient difference between decelerating and accelerating
flow

\begin{tabular}{|c||c|c|c||}
\hline \multirow{2}{*}{ Airfoil section } & \multicolumn{2}{|c|}{$\boldsymbol{C}_{\boldsymbol{T}}$ at decelerating flow is higher than that in accelerating flow by } \\
\cline { 2 - 4 } & For $\boldsymbol{t}_{\boldsymbol{s i n}}$ equal to $4 \mathrm{sec}$ & $\begin{array}{c}\text { For } \boldsymbol{t}_{\boldsymbol{s i n}} \text { equal to } 6 \\
\text { sec }\end{array}$ & $\begin{array}{c}\text { For } \boldsymbol{t}_{\boldsymbol{s i n}} \text { equal to 8 } \\
\text { sec }\end{array}$ \\
\hline NACA0012 & $24 \%$ & $13 \%$ & $12.5 \%$ \\
\hline NACA0015 & $45 \%$ & $-1 \%$ & $12 \%$ \\
\hline NACA0020 & $114 \%$ & $46 \%$ & $13 \%$ \\
\hline NACA0021 & $122 \%$ & $33 \%$ & $20 \%$ \\
\hline
\end{tabular}

6

7 Table 3 A summary of the torque coefficient values at different time periods for the four airfoils

\begin{tabular}{|c|c|c|c|c|c|c|c|c|c|}
\hline \multirow{2}{*}{$\begin{array}{l}\text { Airfoil } \\
\text { section }\end{array}$} & \multicolumn{3}{|c|}{$\mathrm{C}_{\mathrm{T}}\left(t_{\sin }=4 \mathrm{sec}\right)$} & \multicolumn{3}{|c|}{$\mathrm{C}_{\mathrm{T}}\left(t_{\sin }=6 \mathrm{sec}\right)$} & \multicolumn{3}{|c|}{$\mathrm{C}_{\mathrm{T}}\left(t_{\sin }=8 \mathrm{sec}\right)$} \\
\hline & Accelerating & Decelerating & Average & Accelerating & Decelerating & Average & Accelerating & Decelerating & Average \\
\hline NACA0012 & 0.096 & 0.118 & 0.107 & 0.078 & 0.0885 & 0.0834 & 0.073 & 0.0825 & 0.0779 \\
\hline NACA0015 & 0.094 & 0.136 & 0.115 & 0.08 & 0.08 & 0.080 & 0.069 & 0.0773 & 0.0731 \\
\hline NACA0020 & 0.077 & 0.164 & 0.12036 & 0.0675 & 0.099 & 0.0829 & 0.0619 & 0.06984 & 0.0659 \\
\hline NACA0021 & 0.07 & 0.163 & 0.11799 & 0.0676 & 0.0902 & 0.0789 & 0.0608 & 0.0729 & 0.0669 \\
\hline
\end{tabular}


Table 4 The percentage of global entropy generation rate (difference between decelerating and accelerating flow)

\begin{tabular}{|c|c|c|c|}
\hline \multirow{2}{*}{ Airfoil section } & \multicolumn{2}{|c|}{$\boldsymbol{S}_{\boldsymbol{G}}$ at decelerating flow is higher than that in accelerating flow by } \\
\cline { 2 - 4 } & For $\boldsymbol{t}_{\boldsymbol{s i n}}$ equal to 4 sec & For $\boldsymbol{t}_{\boldsymbol{s i n}}$ equal to $\mathbf{6 ~ s e c}$ & For $\boldsymbol{t}_{\boldsymbol{s i n}}$ equal to 8 sec \\
\hline \hline NACA0012 & $34 \%$ & $25 \%$ & $26 \%$ \\
\hline NACA0015 & $33 \%$ & $43 \%$ & $26 \%$ \\
\hline NACA0020 & $35 \%$ & $23 \%$ & $19 \%$ \\
\hline NACA0021 & $31 \%$ & $35 \%$ & $30 \%$ \\
\hline Average value & $33.3 \%$ & $31.5 \%$ & $25.3 \%$ \\
\hline
\end{tabular}

5

Table 5 Comparison between $S_{G}$ for the NACA0015 and other airfoils

\begin{tabular}{|c|c|c|c|}
\hline \multirow{2}{*}{ Airfoil section } & \multicolumn{3}{|c|}{ NACA0015 less than } \\
\cline { 2 - 4 } & NACA0012 & NACA0020 & NACA0021 \\
\hline$t_{\sin }$ equal to $4 \mathrm{sec}$ & $-13 \%$ & $-15 \%$ & $-14 \%$ \\
\hline$t_{\sin }$ equal to $6 \mathrm{sec}$ & $-6 \%$ & $-10 \%$ & $-15 \%$ \\
\hline$t_{\sin }$ equal to $8 \mathrm{sec}$ & $-11 \%$ & $-15 \%$ & $-18 \%$ \\
\hline
\end{tabular}

7

8 Table 6 A summary of the global entropy generation rate values at different time periods for the four airfoils

\begin{tabular}{|c|c|c|c|c|c|c|c|c|c|}
\hline \multirow{2}{*}{$\begin{array}{l}\text { Airfoil } \\
\text { section }\end{array}$} & \multicolumn{3}{|c|}{$S_{G}(\mathrm{~kW}) t_{\sin }=4 \mathrm{sec}$} & \multicolumn{3}{|c|}{$S_{G}(\mathrm{~kW}) t_{\sin }=6 \mathrm{sec}$} & \multicolumn{3}{|c|}{$\mathrm{S}_{\mathrm{G}}(\mathrm{kW}) t_{\sin }=8 \mathrm{sec}$} \\
\hline & Accelerating & Decelerating & Average & Accelerating & Decelerating & Average & Accelerating & Decelerating & Average \\
\hline NACA0012 & 0.0505 & 0.06785 & 0.05918 & 0.05 & 0.063 & 0.0567 & 0.0496 & 0.06265 & 0.0561 \\
\hline NACA0015 & 0.0444 & 0.05899 & 0.0517 & 0.0437 & 0.0625 & 0.0531 & 0.04434 & 0.0557 & 0.05003 \\
\hline NACA0020 & 0.05152 & 0.06958 & 0.0606 & 0.053 & 0.065 & 0.0589 & 0.0535 & 0.0639 & 0.0587 \\
\hline NACA0021 & 0.05239 & 0.06844 & 0.0604 & 0.053 & 0.072 & 0.062 & 0.05302 & 0.0687 & 0.06086 \\
\hline
\end{tabular}

10 